\title{
Crack-based and Hair-like Sensors Inspired from Arthropods: A Review
}

\author{
Changchao Zhang ${ }^{1}$, Junqiu Zhang ${ }^{1,2}$, Daobing Chen ${ }^{3}$, Xiancun Meng ${ }^{1}$, Linpeng Liu ${ }^{1}$, Kejun Wang ${ }^{4}$, Zhibin $^{1}$ \\ Jiao $^{1}$, Tao Sun ${ }^{1}$, Dakai Wang ${ }^{1}$, Shichao Niu ${ }^{1,2^{*}}$, Zhiwu Han ${ }^{1 *}$, Luquan Ren ${ }^{1}$ \\ 1. Key Laboratory of Bionic Engineering (Ministry of Education, China), Jilin University, Changchun 130022, China \\ 2. State Key Laboratory of Automotive Simulation and Control, Jilin University, Changchun 130022, China \\ 3. State Key Laboratory of Materials Processing and Die \& Mould Technology, School of Materials Science and Engineering, Huazhong \\ University of Science and Technology, Wuhan 430074, China \\ 4. School of Mechanical and Electric Engineering, Jiangsu Provincial Key Laboratory of Advanced Robotics, Soochow University, \\ Suzhou 215123, China
}

\begin{abstract}
Over a long period of time, arthropods evolve to have two excellent mechanical sensilla of slit sensilla and trichobothria sensilla, which construct a perfect perception system. The former mainly perceives the change of the in-the-plane force while the latter perceives that of the out-of-plane force. In recent years, these two sensilla have attracted researchers as the models for developing artificial mechanical sensors. This review mainly includes the biomechanics and biomimetic manufacturing techniques as well as their future application value. In order to better understand the advantages of biological strategies, this review describes the morphology, mechanical analysis, and information recognition of slit sensilla and trichobothria sensilla. Then this review highlights the recent development of Crack-based Sensors (CBSs) and Hair-like Sensors (HLSs) based on the analysis of biological mechanism. The manufacturing method and substrate of crack in CBS and those of hair rods in HLS are discussed respectively. Finally, the practical applications and potential value of two sensilla, such as flexible wearable electronic devices, robot sensing system, autopilot sensing and wind tunnel speed detection, are briefly discussed.
\end{abstract}

Keywords: crack-based sensors, hair-like sensors, slit sensilla, trichobothria sensilla, bioinspiration

Copyright (C) The author(s) 2020.

\section{Introduction}

Over billions of years of evolution, arthropods have had an admirable perceptual ability for survival. With the development of technology, researchers have created many excellent sensing devices by continuously learning from nature. In recent years, researchers have been paying more and more attention to biological sensory system, especially the mechanical sensilla of arthropods. From imitating external forms to imitating internal mechanisms, people have developed mechanical sensors with high sensitivity ${ }^{[1]}$, low power consumption ${ }^{[2]}$ and high compatibility ${ }^{[3]}$. However, we still have a lot of challenges in comprehensively understanding existing sensors. For example, we need to learn more about biology to create more stable sensors.

Slit sensilla and trichobothria sensilla are ultra-sensitive sensory organs in some arthropods (e.g., spiders and scorpions $)^{[4-7]}$. These two sensilla have a large difference in the division of labor. The slit sensilla mainly perceives in-the-plane strain to accept nearby information ${ }^{[8]}$, such as vibration ${ }^{[5,9]}$. The trichobothria sensilla mainly perceives the forces generated by the out-of-plane flow to accept nearby information, such as air flow rate ${ }^{[6]}$. The two sensilla work together to help arthropods better locate natural enemies, prey and spouses for the best possible survival ${ }^{[4,10]}$. Therefore, the simulation of these excellent biomechanical sensilla will provide a new and important idea for developing artificial sensors. Taking spiders and scorpions as examples, we separately present the morphological structure, mechanical analysis and energy efficient transformation process of these two sensilla, as well as recent biomimetic mechanical sensors that are based on these two sensors.

Crack-based Sensor (CBS) mainly perceives strain parameters ${ }^{[1]}$. The base material is diverse, and the common materials can be classified into a variety of

\footnotetext{
*Corresponding author: Shichao Niu, Zhiwu Han

E-mail: niushichao@jlu.edu.cn, zwhan@jlu.edu.cn
} 
substrates, which can be commonly classified into poly-urethane acrylate (PUA), polydimethylsiloxane (PDMS), polyethylene terephthalate (PET), and paper. The process of making cracks in CBS can be mainly divided into stretching, bending and drying, and the number, length, width, depth, and density of the cracks play a key role in the performance of the CBS. This review adds the latest Hair-like Sensor (HLS) and details the sensor fabricating method based on the micrometer and millimeter size. In addition, we also introduce other applications of HLS, such as strain sensing, tactile sensing and acceleration sensing. This review has a reference value for the rational design and fabrication of CBS and HLS in the practical engineering applications. Finally, some practical applications and future prospects of these two sensors are briefly introduced.

\section{Slit sensilla and CBS}

Changes in mechanical signals in the environment greatly affect animal life activities, such as ground vibration and air flow. There is also competition in the field of information reception, and creatures that are more sensitive to information are usually able to win. After 400 million years of evolution, arthropods such as spiders and scorpions have become leaders in the mechanical information detection ${ }^{[5]}$. In the natural environment, mechanical stimuli can be divided into plane inner forces and plane outer forces in space. These two mechanical stimuli provide arthropods with a wealth of outside information to enable them to respond to the external environment. They have evolved a variety of mechanical receptors for predation, courtship and escaping natural enemies, such as slit sensilla and trichobothria sensilla. In this section, we select different arthropods to discuss the structural characteristics, mechanical analysis, and information transfer of slit sensilla.

\subsection{Slit sensilla of arthropods (spiders and scorpi- ons)}

2.1.1 Distribution and morphology of slit sensilla

Spiders have a typical slit structure and are the most thoroughly studied arthropods. The types and the distribution of slit sensilla of different arthropods are very similar to each other. The spider slit sensilla were fully analyzed by Barth ${ }^{[5]}$. Taking spider Cupiennius salei ${ }^{[4]}$ (Fig. 1a) as an example, which is a large Central American wandering spider that lives on plants such as bromeliad plants ${ }^{[6]}$. Fig. 1 shows the distribution of cracks in spiders. The vast majority ( $86 \%)$ is located in the legs and pedipalps, embedded in sclerotized exocuticle, and the soft mesocuticle is around the crack. Like other arthropods, the slit sensilla organs of spider can be divided into three types according to the arrangement of the slits: (i) isolated single slits, (ii) several slits of the loose group, and (iii) composite or lyriform organs (Figs. $1 \mathrm{~b}-1 \mathrm{~d}$ ). In Cupiennius salei, about half of the slits are isolated or part of a loose group, and the other half forms a total of 144 lyriform organs: 134 on the walking legs and pedipalps, 10 on spinnerets and chelicerae ${ }^{[4]}$. For the slit distribution position, the slit located in the walking foot is able to detect the vibration of the surrounding environment. Many researchers have studied the cracks in the joint of the legs, and most lyriform organs are very close to the joint. Fig. 1 shows the cover membrane of two lyriform organs: the vibration sensitive metatarsal lyriform organ (HS10) and the proprioreceptive tibial lyriform organ (HS8) ${ }^{[8]}$. The distal end of the lyriform organ of the metatarsus is a pad that cushions the joint between the metatarsus and tarsus. The tissue pad has a crescent shape with cuticle thickness of approximately $100 \mu \mathrm{m}$ (Figs. 1e and 1f) ${ }^{[9]}$. It has also been found that the pad plays a key role in HS10 compression (stimulation), including large initial deformation caused by the tarsus (tens of $\mu \mathrm{m}$ ) into smaller deformation (tens of $\mathrm{nm})^{[8]}$.

Different arthropods have different living environments, but their slit structures are similar. Further, different arthropods have similar slit structures, but the number of slit structures is different. Barth and Wadepuhl ${ }^{[10]}$ found that the number of slit sensilla in spiders, scorpions, and whip spiders differed greatly, mainly reflected in the total number of slits, the ratio of a single slit and the proportion of lyriform organ group. Where the spider has lyriform organs, the scorpion has only groups of single slits. There are 352 slits on the Cupiennius salei's legs, and there are only 58 slits or 45 slits on the scorpion's walking leg legs ${ }^{[4]}$.

For the scorpion, the slit structures on the scorpion legs are less orderly arranged compared to the slit structures on the spider legs. The legs and pedipalps of 

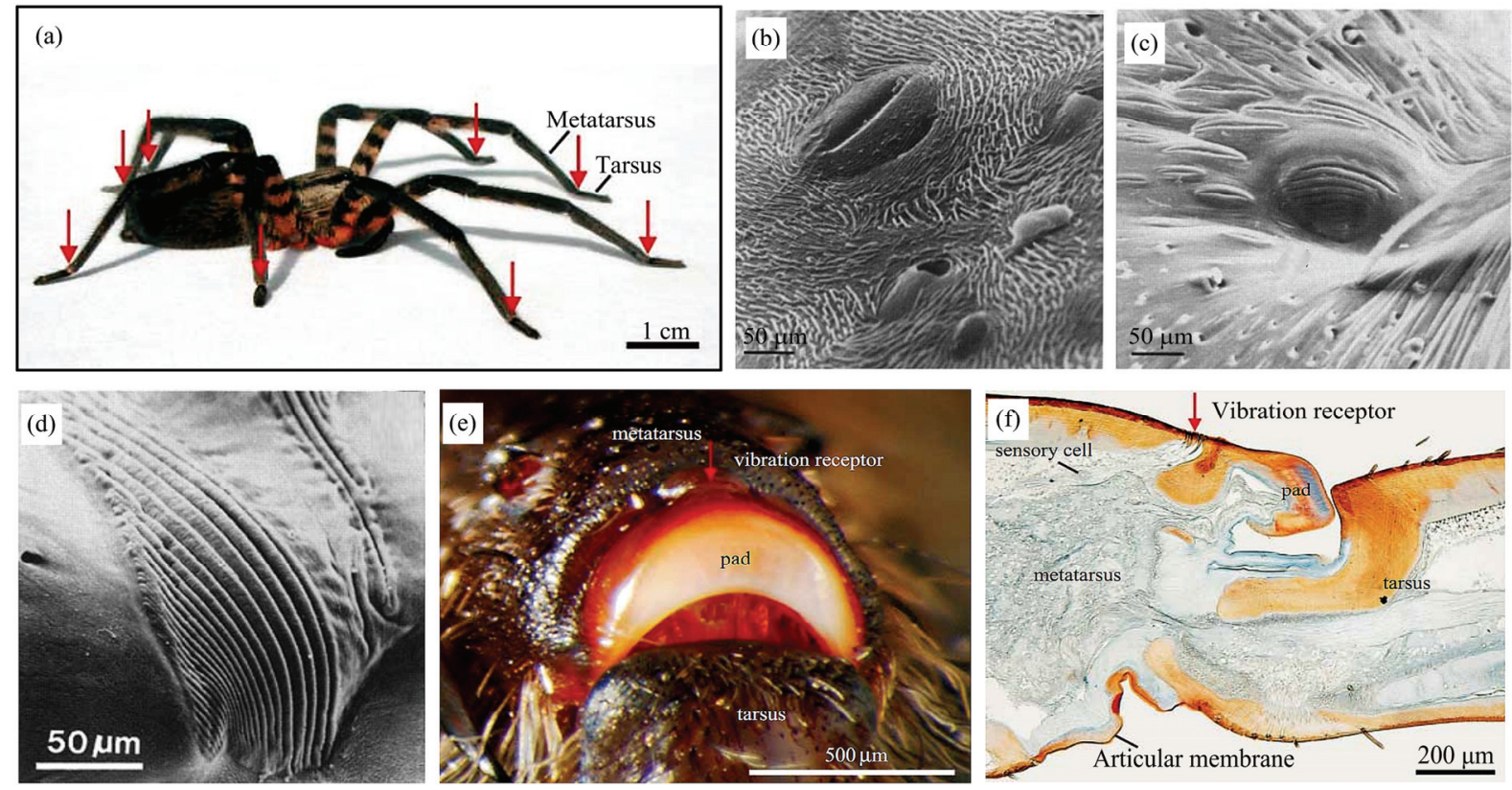

Fig. 1 (a) Optical image of the spiders (Cupiennius salei) ${ }^{[9]}$ and (b-d) three types of spider slit sensilla ${ }^{[4]}$. (b) Isolated single slits; (c) several slits of the loose group; (d) composite or lyriform organs; (e) mechanical signal receiver is located between the pad and the metatarsus ${ }^{[9]}$. (f) The cross-section of the leg joints is stained with Mallory, and the blue part indicates a moderately hardened stratum corneum. Mechanical signal receiver is dominated by nerve cells ${ }^{[9]}$.

the scorpion have not lyriform organs. Only isolated single slit and grouped slit distributed on the legs of the scorpion, and their arrangement are also regular. Such groups of organs are easily observed under the microscope because they are in a clear position and show a specific pattern of slit arrangements. On the surface of the scorpion, the isolated crack is significantly more than the spider. In spiders, the femur is the most abundant in isolated slits. In addition, the isolated slits of the spider are usually arranged in lines on the posterior and posterior sides of the legs, while in the scorpion, they were found to be distributed irregularly on the sides of the legs ${ }^{[4]}$. As arthropod, the scorpion has a typical slit sensilla, the Basitarsal Compound Slit Sensilla (BCSS), and the BCSS array structure detect nanometer amplitude mechanical signals ${ }^{[11]}$. For more than half a century, people have discovered the outstanding perception function of BCSS in prey positioning through behavioral and physiological analysis ${ }^{[12,13]}$. Morphology, distribution and physical structure of the slit sensilla are specifically described below. Different types of scorpions have different sizes of slit structures, but the slits are in the same position. The number of slit in BCSS is 12 , and the shape of the slit is slightly curved. As shown in
Fig. 2c, the long axes of the different slit structures are not paralleled, the maximum angle $\theta$ between the long axes has exceeded $90^{\circ}$. The non-parallel array structure makes it easier to feel the signals from around the body and precise positioning of prey and natural enemies. Taking the $H$. petersii (Fig. 2a) as an example, this scorpion mainly lives in the Asian rainforest region. As shown in Fig. 2b, the position of the slit located at the end of the second segment of each walking leg, and the position of the slit is between the tarsus and the basitarsus. Fig. $2 \mathrm{~d}$ shows the BCSS cross section in the dehydrated state and the internal structure of the slit sensilla. The BCSS consists of two exoskeleton cuticle and a thin cuticular membrane between them. The exoskeleton cuticle is divided into two parts: the epicuticle and the procuticle (Fig. 2e). As shown in Fig. 2f, the film is part of the epicuticle and there are no obvious structural differences between them ${ }^{[14]}$.

The position, direction, length and number of slit sensilla between the same species vary very little ${ }^{[15]}$. In the example of the study, the common feature of spiders and scorpions is that the slit sensilla are mainly concentrated at the joints. From the perspective of the collection of mechanical signals from arthropods, the distribution 


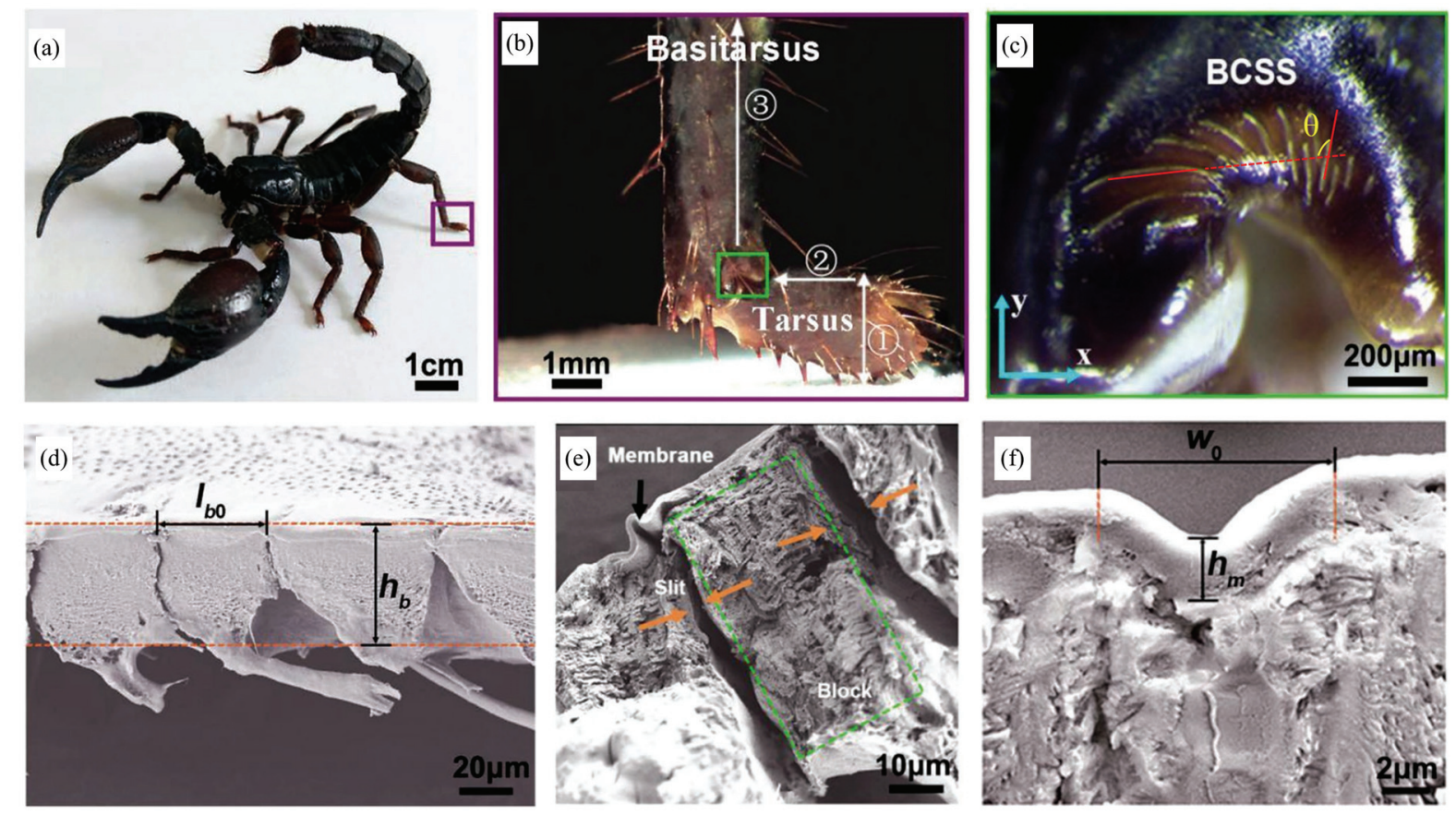

Fig. 2 The basitarsal compound slit sensilla ${ }^{[14]}$. (a) Optical image of the scorpion (H. petersii); (b) mechanical perception of slit sensilla; (c) the basitarsal compound slit sensilla optical image at the end of basitarsus; (d-f) SEM images of different magnifications of slit sensilla (vertical section).

is reasonable. The joint is equivalent to a fulcrum, and is also the best point to feel the mechanical force, making spiders and scorpions easier to receive mechanical stimulation from the external environment.

\subsubsection{Mechanical analysis of slit sensilla}

In order to understand the mechanical significance of the spider slit arrangement, Barth and Stagl ${ }^{[15]}$ mimicked the stress state of the spider exoskeleton slit by measuring the deformation of the plastic disc with the slit structure. Different slits are arranged by cutting on a plastic disc, applying a static load to the disc in different directions, and applying a precise load to the disc by adjusting the loading angle. The experiment found that under appropriate stimulation, the value of the slit compression is much higher than the value at the time of expansion, and it is found that the value of the load is the highest when it is at right angles to the slit axis. The length distribution and lateral displacement of the slit in the model have significant effect on the slit deformation ability. In the arrangement of cracks of the same length and conventional lateral displacement, the deformation of all the slits in all load directions is very similar. Fratz ${ }^{[16]}$ explains the enlargement mechanism of the slit structure through the mechanics of tessellations. As shown in Fig. 3a, each spider slit can be roughly approximated as a strain amplification system ${ }^{[16]}$. The first thing to understand is that the strain in the soft tissue between the rigid blocks is compared with the strain in the composite system. The blocks are much stiffer than the slit between them. The total strain of the composite $\varepsilon_{\mathrm{C}}$ can be used as a function of the elongation strain of the width of the slit $\varepsilon_{\mathrm{S}} . L_{\mathrm{B}}$ and $L_{\mathrm{S}}$ are the lengths of the rigid block (the orange part in Fig. 3a) and the soft slit (grey part in Fig. 3a), respectively:

$$
\varepsilon_{\mathrm{C}}=\varepsilon_{\mathrm{S}} L_{\mathrm{S}} /\left(L_{\mathrm{B}}+L_{\mathrm{S}}\right) .
$$

When $L_{\mathrm{S}}$ is smaller than $L_{\mathrm{B}}$, it is obvious that the strain in the slit is larger than the overall strain. It is easy to conclude that when the ratio of $L_{\mathrm{B}} / L_{\mathrm{S}}$ is 100 , the strain of the slit will be expanded by 100 times. This means that the vibrational oscillation strain is larger in the slit than that in the composite structure, making it easier to measure $^{[17]}$. This means that we can mimic the arthropod slit sensilla to create a highly sensitive vibration sensor ${ }^{[18]}$. With the development of finite-element analysis software, Hößl et al. explains the mechanical significance of different slit arrays through finite-element modeling ${ }^{[19]}$. 

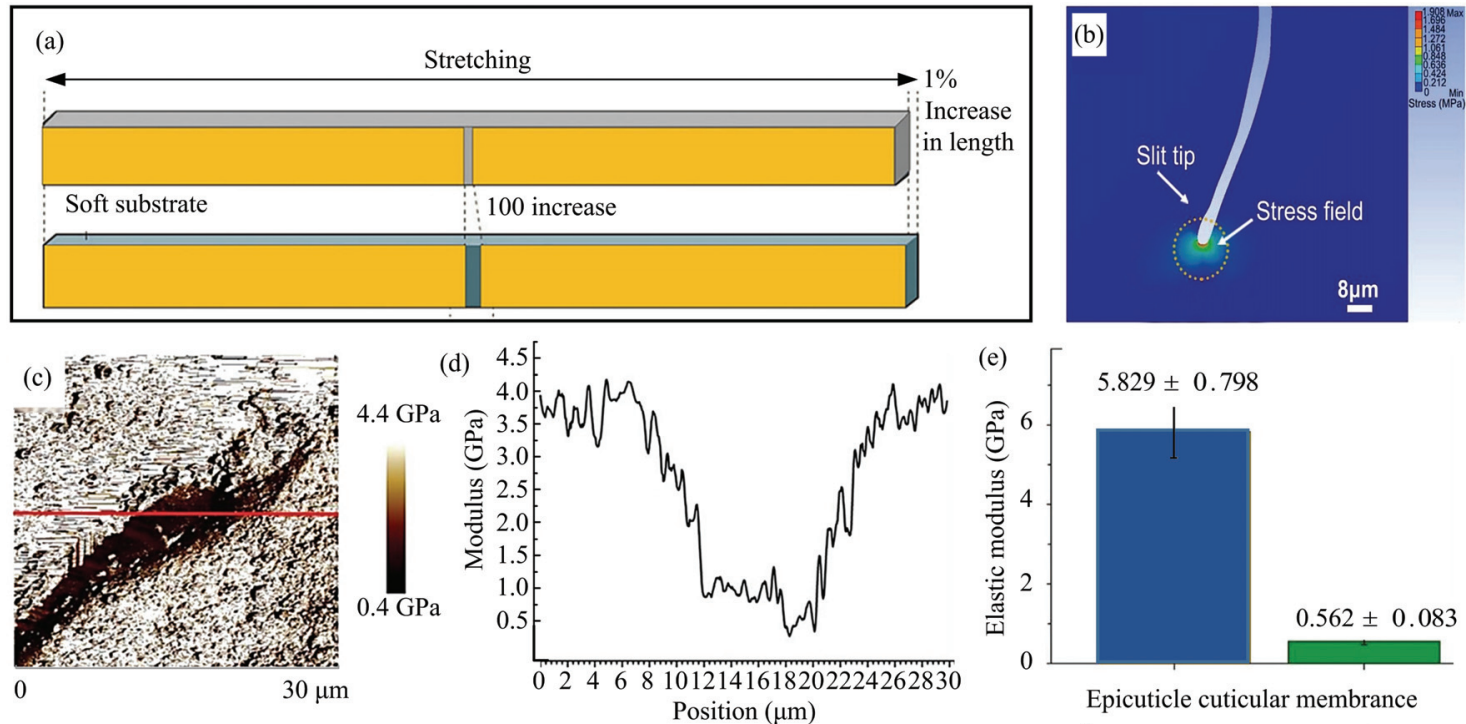

Fig. 3 (a) The schematic diagram of the signal amplification of the slit structure by the mechanics of tessellations ${ }^{[14]}$. (b) Stress field near the crack tip ${ }^{[14]}$. (c) Elastic modulus distribution map obtained by the Atomic Force Microscope (AFM) peak-force Quantitative Nanomechanical Mapping (QNM) mode, at a local region of the BCSS near the tip of the slit ${ }^{[14]}$. (d) The cross-sectional view of the elastic modulus data is obtained from the position shown by the red line in Fig. $\mathrm{d}^{[14]}$. (e) The elastic modulus of the epicuticle and the cuticular membrane are represented by blue and green, respectively ${ }^{[14]}$.

Through the finite-element analysis, the displacement changes of the different shape slit are compared, which are straight slit, C-shaped slit and S-shaped slit. Among the geometric parameters studied, the straight face produces the largest relative displacement under the compressive load. In terms of fracture mechanics, the stress at the tip of the slit is significantly amplified to a stress value close to the mathematical singularity ${ }^{[20]}$. As the show in Fig. 3b, through the fracture mechanics, we also know that the slit structure will form a singular stress field near the tip of the applied stress crack, realizing the concentration of stress ${ }^{[14]}$. For arthropods, the slit sensilla tip can collect mechanical signals from the surrounding environment and play an important role in the next signal transmission. However, in common sense, the concentration of energy in the slit will inevitably lead to further cracking of the slit, eventually leading to complete failure of the slit sensilla. However, arthropods such as spiders and scorpions seem to find reasonable solutions. In order to understand the fracture resistance of the slit sensilla, the elastic modulus is first analyzed. Taking the BCSS of the scorpion as an example for analysis. As shown in Fig. 3d, elastic modulus data obtained from the position indicated by the red line from Fig. 3c, the elastic modulus of different areas of the outer surface of the seam is exhibited ${ }^{[14]}$. The BCSS is covered by a flexible epidermal membrane. The nanoindentation testing confirmed that the skin elastic modulus $E_{\mathrm{b}}$ and the epidermal membrane $E_{\mathrm{m}}$ were $5.829 \mathrm{GPa} \pm 0.798 \mathrm{GPa}$ and $0.562 \mathrm{GPa} \pm 0.083 \mathrm{GPa}$, respectively (Fig. 3e). The membrane covering the slit may contain more moisture, making it have higher toughness to withstand cyclic loading and avoid fatigue failure. When inhibiting further fracture of the slit, the cuticular membrane acts as a bridge to suppress the excessive opening of the fracture under high-tensile stress. It is worth noting that the membrane is deformed by bending when it prevents further cracking, rather than simple planar stretching or compression deformation.

\subsubsection{Energy transformation and information recogni-} tion of slit sensilla

In arthropods, such as spiders and scorpions, the basic anatomical and microscopic structures of the crevices have common features. The basic anatomy and microstructure of arthropod slit sensilla share common characteristics, such as spiders and scorpions ${ }^{[4]}$. From the perspective of energy conversion, the slit sensilla is equivalent to a transducer element that converts the mechanical energy transmitted into electrical energy. 
The conversion efficiency of the transducer element depends on the efficient collection of external mechanical energy and the efficient conversion of energy. Obviously, arthropods already possess the power of efficient transformation, which subtly distributes neurons to the two tips of the slit sensilla. From the upper part, the position of the tip of slit is prone to energy concentration. As shown in Fig. 4a, a cross-sectional view of a pair of mechanically sensitive dendrites is shown, and dendrites is located at the tip of the slit sensilla of spider ${ }^{[4,21,22]}$. At the tip of each slit, there are two bipolar neurons, both of which extend toward the tip of the slit and are ultimately coupled to the outer membrane. Taking the lyriform organ (VS-3) on anterolateral leg patella of the spider as an example, the two bipolar neurons associated with each slit have relatively large fusiform bodies with diameters ranging from $20 \mu \mathrm{m}$ to over $100 \mu \mathrm{m}$ (Fig. $4 \mathrm{~b})^{[23]}$. The dendrites gather at the tip to form a coupling cylinder, as shown in the asterisk of Fig. 4b. For the scorpion, this coupling cylinder was also found, as shown in Figs. 4c-4e. Each slit structure will have a coupling cylinder, which is also located in the concentrated area of stress (Fig. 4f). It is worth noting that bipolar neurons have two completely differently distributed neurons, the left neuron is the type A neuron, and the right neuron is the type $\mathrm{B}$ neuron. The dendrites of the B neuron extend completely through the slit and are coupled to the outer membrane by a coupling cylinder. However, the dendrites of A neuron are shorter and terminate near the intima at the entrance to the slit ${ }^{[24]}$. When the stimulation probe is used to stimulate the tip region of the slit, they are all capable of receiving external mechanical stimulation and energy conversion $^{[25,26]}$. These two different dendrites have different effects on the acceptance and transformation of mechanical energy. External mechanical stimulation causes two neurons to produce action potentials, but they have different time processes. The type A neuron reacts quickly and produces only 1 or 2 action potentials, while the type $\mathrm{B}$ neuron generates the burst ${ }^{[25]}$.

\subsection{Bionic crack-based strain sensor}

With the development of flexible sensors, some flexible high-sensitivity mechanical sensors based on inorganic silicon ${ }^{[26-28]}$, organic semiconductor ${ }^{[29-31]}$, pressure sensor $^{[32]}$ and self-powered devices ${ }^{[33,34]}$ are
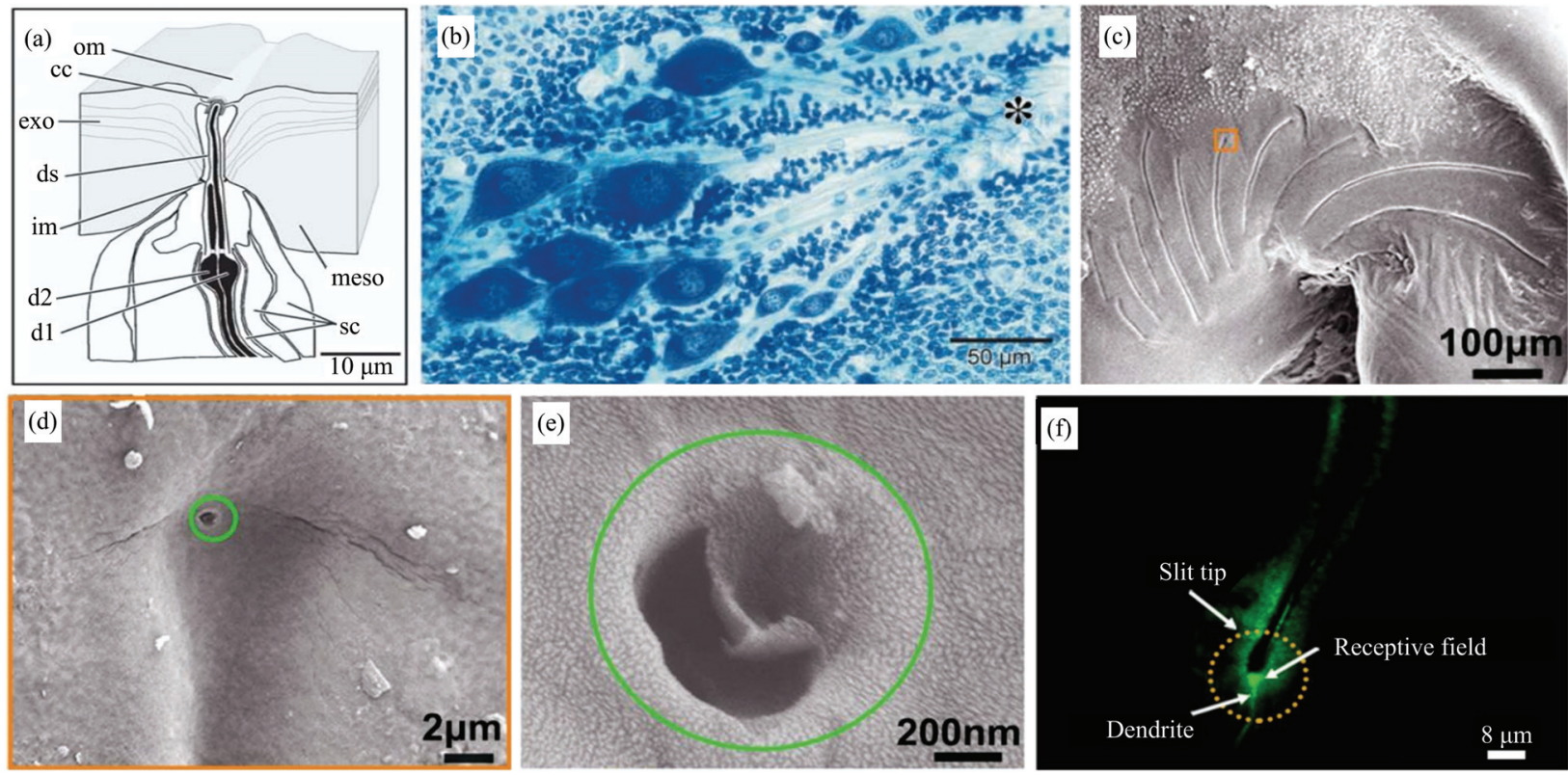

Fig. 4 Arthropod slit sensilla neuron distribution map. (a) A cross-sectional view of a pair of mechanically sensitive dendrites at the tip of a spider's slit sensilla. Letter from top to bottom: om is outer membrane, cc is coupling cylinder, exo is exocuticle, ds is dendritic sheath, $\mathrm{im}$ is inner membrane, meso is mesocuticle, $\mathrm{d} 1$ and $\mathrm{d} 2$ are dendrites, sc is glial sheath cells ${ }^{[21]}$; (b) methylene blue-stained VS-3, showing the pair of spindle-shaped neuron bodies and their dendrites extending to the tip of the slit ${ }^{[21]}$; (c) SEM image of the BCSS, the orange rectangle is the coupling cylinder ${ }^{[14]} ;(\mathrm{d})$ a partially enlarged image taken from $(\mathrm{c})^{[14]}$. (e) a partially magnified image taken from (b) ${ }^{[14]}$; (f) Confocal Laser Scanning Microscopy (CLSM) images indicate that dendritic terminals of neurons are distributed near the tip of the slit ${ }^{[14]}$. 
applied to flexible robots. However, flexible sensors still present challenges in high sensitivity, high flexibility and high durability ${ }^{[18]}$. In addition to developing new materials, building biomimetic high-performance sensors is also a viable strategy. Arthropods such as spiders and scorpions can use the slit sensilla near their leg joints to sense infinitesimal mechanical stress changes, which provides new ideas for the fabrication of strain sensor. Through mimicking the slit structure of arthropods, a series of highly sensitive biomimetic sensor is fabricated while achieving high sensitivity and high flexibility. This is an excellent strategy for building flexible and scalable structures that can accommodate large strains and geometric distortions such as bending and twisting. In the past five years, people have made major breakthroughs in strain sensors with high sensitivity, high flexibility and high flexibility by mimicking the slit sensilla.

In order to adapt to the challenges of more sensitive sensors, researchers have been trying to develop advanced materials such as Carbon Nanotubes $(\mathrm{CNTs})^{[35,36]}$, carbon composites ${ }^{[37,38]}$, organic semiconductor $^{[39,40]}$, nanowires ${ }^{[27,41,42]}$ and nano/microscale structural design ${ }^{[43,44]}$. A series of ultra-sensitive crack-based strain sensors was fabricated by using different crack generation methods (Table 1). The working principle of the crack-based strain sensor is attributed to the change in resistance caused by reconnection-disconnection of cracks fracture surfaces. The crack-based strain sensor has a two-part structure: an elastomeric substrate and a brittle conductive layer. The former provides stretchability and the latter generates cracks. However, there is a large difference in the selection of the elastomeric substrate and the brittle conductive layer. Material selection determines the sensitivity and function of the CBS sensor. This section mainly introduces the crack-based sensor composed of different materials, and the preparation method and characteristics of the crack.

\subsubsection{Polyurethane acrylate based crack sensor}

Polyurethane acrylate (PUA) is formed by a variety of hydrogen bonds between polymer molecular chains, so that the PUA film has excellent mechanical wear resistance, flexibility, and high elongation at break. In general, ultra-sensitive crack-based strain sensors have two different material properties, such as differences in elastic modulus. Among them, the material with smaller elastic modulus plays the role of flexible bending, while the material with larger elastic modulus plays the role of strain sensing. Strain sensing materials usually use metal film. Compared with metal film, PUA has the characteristics of low modulus of elasticity. Further, the high elastic modulus material can be brittlely fractured by simply bending, resulting in uniform parallel cracks. Then, the strain changes the resistance of the sensor through the reconnection-disconnection of the crack. Kang et al. demonstrated a flexible sensor based on nanoscale crack connection by mimicking the spider's slit sensilla, and obtained ultra-sensitivity corresponding to strain and vibration ${ }^{[18]}$. A strain sensor is designed by depositing a $20 \mathrm{~nm}$ thick layer of platinum (Pt) on top of a viscoelastic polymer, polyurethane acrylate (PUA) ${ }^{[45]}$. As shown in Fig. 5a, a bending stress is applied to the $\mathrm{Pt}$ on the PUA to form a controlled crack density and direction. Under the mechanical stress of different bending radius of curvature ( $1 \mathrm{~mm}, 2 \mathrm{~mm}$ and $3 \mathrm{~mm}$ ), the transverse crack is formed on the applied stretching force (Fig. 5b). Due to the contact and disconnect of the crack on the Pt film, the conductivity changes greatly, so that the small strain can form a large resistance change. Different Pt film thicknesses make the sensor react differently, such as a $100 \mathrm{~nm}$-thick Pt film has obvious hysteresis. Different properties of the metal film form different crack shapes. The $20 \mathrm{~nm}$ thick Au film has been same bending with a radius of curvature of $1 \mathrm{~mm}$, and the $\mathrm{Au}$ film does not generate similar straight crack. Both the as prepared Au film and the bend film generate random island cracks. However, the irregular island structure is significantly less sensitive than the straight-through nanoscale cracks. The sensors based on the near cut through straight cracks with nanoscale, has a gauge factor of over 2000 in the $0-2$ percent strain range.

Although this spider-inspired CBS has a high sensitivity, the relationship between GF sensitivity and crack geometry is still unclear, such as crack depth. After that, the sensitivity of the nanoscale crack-based sensor is increased to about 16,000 GF by adjusting the crack depth on the basis ${ }^{[46]}$. The gauge factor of this sensor is higher than that of strain sensors based other mechanisms ${ }^{[35,47]}$. Further, it was found that the variation of the density and roughness of the crack was minimally 
Table 1 Summary of crack-based strain sensors based on different fabrication principles

\begin{tabular}{|c|c|c|c|c|c|c|c|c|c|}
\hline $\begin{array}{c}\text { Serial } \\
\text { number }\end{array}$ & Crack size & Base material & $\begin{array}{l}\text { Strain respon- } \\
\text { sive material }\end{array}$ & $\begin{array}{l}\text { Conductive layer thick- } \\
\text { ness }\end{array}$ & $\begin{array}{c}\text { Method of } \\
\text { creating cracks }\end{array}$ & $\begin{array}{l}\text { Gauge } \\
\text { factors }\end{array}$ & $\begin{array}{l}\text { Strain } \\
\text { range }\end{array}$ & $\begin{array}{l}\text { Durability } \\
\text { (Cyclic } \\
\text { strain test) }\end{array}$ & Ref. \\
\hline 1 & Nanoscale & PUA & $\mathrm{Pt}$ & $20 \mathrm{~nm}$ & Bending & $>2,000$ & $0 \%-2 \%$ & $>5,000$ & {$[18]$} \\
\hline 2 & Nanoscale & PUA & $\mathrm{Pt}$ & $20 \mathrm{~nm}$ & Bending & $>16000$ & $0 \%-2 \%$ & $>10000$ & [46] \\
\hline 3 & Microscale & C-PUA & $\mathrm{Cr}$ and $\mathrm{Pt}$ & $\mathrm{Cr}(10 \mathrm{~nm}) ; \mathrm{Pt}(20 \mathrm{~nm})$ & Stretching & $2 \times 10^{6}$ & $10 \%$ & $>5000$ & [49] \\
\hline 4 & Nanoscale & $\begin{array}{l}\text { PUA and self-healable } \\
\text { polymer }\end{array}$ & $\mathrm{Pt}$ & $20 \mathrm{~nm}$ & Bending & 2102 & $0 \%-2 \%$ & $>10^{6}$ & {$[51]$} \\
\hline 5 & Microscale & PDMS & Ag nano-ink & $356 \mathrm{~nm}$ & Drying & 2.05 & $0 \%-20 \%$ & $>1,000$ & {$[60]$} \\
\hline 6 & Microscale & PDMS & $\mathrm{Ti} / \mathrm{Au}$ & $\mathrm{Ti}(10 \mathrm{~nm}) ; \mathrm{Au}(50 \mathrm{~nm})$ & Prestretching & 5000 & $1 \%$ & $>700$ & {$[61]$} \\
\hline 7 & Nanoscale & PDMS & $\mathrm{VO}_{2}$ & $100 \mathrm{~nm}$ & Stretching & 400 & $0.1 \%$ & $>10000$ & {$[62]$} \\
\hline 8 & Nanoscale & PDMS & Ag nanowire & - & Stretching & 30 & $100 \%$ & $>2500$ & {$[67]$} \\
\hline 9 & Microscale & PDMS & CNTs & - & Prestretching & 87 & $100 \%$ & $>1500$ & {$[66]$} \\
\hline 10 & Nanoscale & PDMS & $\mathrm{Pt}$ & - & Bending & 30 & $150 \%$ & - & {$[68]$} \\
\hline 11 & - & PDMS & $\mathrm{Cr}$ and $\mathrm{Au}$ & $\mathrm{Cr}(10 \mathrm{~nm}) ; \mathrm{Au}(40 \mathrm{~nm})$ & Prestretching & $10^{8}$ & $0.01 \%$ & $>1000$ & {$[1]$} \\
\hline 12 & Microscale & PDMS & $\mathrm{Au}$ & $50 \mathrm{~nm}$ & $\begin{array}{l}\text { Template trans- } \\
\text { ferring }\end{array}$ & 5888.89 & $2 \%$ & $>50$ & [69] \\
\hline 13 & Nanoscale & PET & $\begin{array}{l}\text { Indium tin } \\
\text { oxide }\end{array}$ & $600 \mathrm{~nm}$ & Stretching & 4000 & $2 \%$ & $>5000$ & [78] \\
\hline 14 & Nanoscale & PET & $\mathrm{Au}, \mathrm{Ag}$ or $\mathrm{Pt}$ & $20 \mathrm{~nm}$ & Stretching & 1600 & $2 \%$ & $>5000$ & [79] \\
\hline 15 & Microscale & Glossy paper & $\begin{array}{l}\text { Carbon black } \\
\text { ink }\end{array}$ & - & Bending & 647 & - & $>70000$ & [84] \\
\hline 16 & Microscale & Paper & Graphite glue & $20 \mu \mathrm{m}$ & $\begin{array}{l}\text { Thermal an- } \\
\text { nealing }\end{array}$ & 804.9 & $0.038 \%$ & $>10000$ & [93] \\
\hline 17 & Microscale & Abrasive paper & $\mathrm{Au}$ & - & Bending & 75.8 & $0.59 \%$ & $>18000$ & [94] \\
\hline 18 & Nanoscale & Polyimide & $\begin{array}{c}\mathrm{MoO}_{3}, \mathrm{Cr} \text { and } \\
\mathrm{Au}\end{array}$ & $\begin{array}{c}\mathrm{MoO}_{3}(5 \mathrm{~nm}) ; \mathrm{Cr}(50 \\
\mathrm{nm}) ; \mathrm{Au}(30 \mathrm{~nm})\end{array}$ & Stretching & $>10000$ & $2 \%$ & $>15000$ & [95] \\
\hline 19 & Microscale & Polyimide & Carbon black & $\mathrm{PI} / \mathrm{CB}(20 \mu \mathrm{m})$ & Bending & 470 & $0.2 \%$ & $>150$ & [96] \\
\hline 20 & Microscale & Ecoflex elastomer & Graphite & $5 \mu \mathrm{m}$ & Oxygen & $\geq 100$ & $\geq 50 \%$ & $>2000$ & [98] \\
\hline 21 & Microscale & $\begin{array}{c}\text { Thermoplastic polyure- } \\
\text { thane }\end{array}$ & $\begin{array}{l}\text { AgNWs and } \\
\text { reduced gra- } \\
\text { phene oxide } \\
\text { hybrid parti- } \\
\text { cles }\end{array}$ & $10 \mu \mathrm{m}$ & Prestretching & 4000 & $1 \%$ & $>1000$ & [97] \\
\hline
\end{tabular}

Note: The reason for the difference in the sensitivity of serial number 1 and serial number 2 is the difference in crack depth.
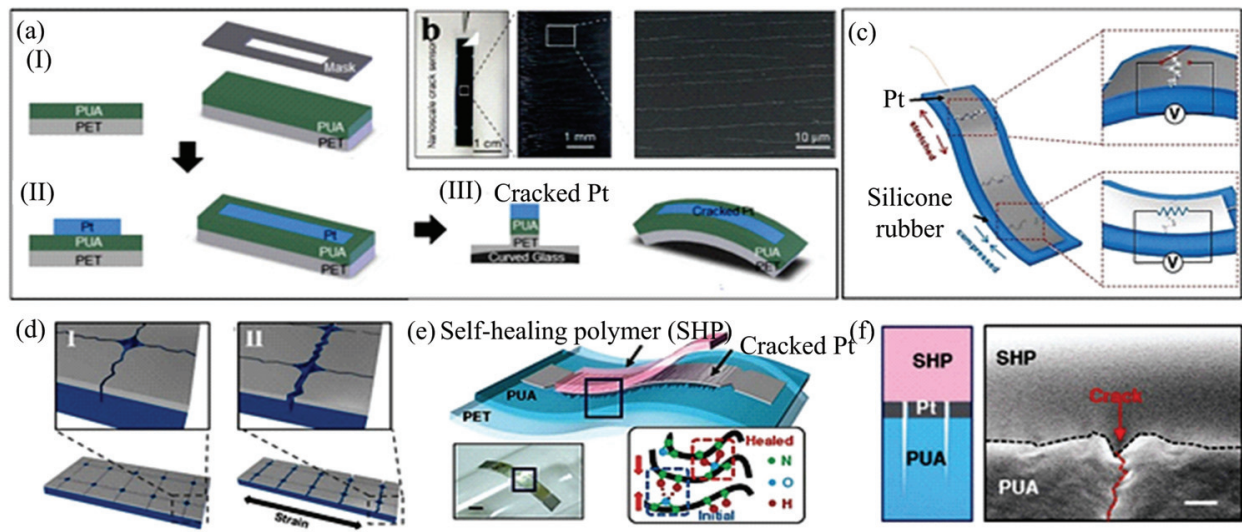

Fig. 5 Schematic diagram of crack-based sensor based on PUA. (a) The process of bending to create a crack ${ }^{[18]}$; (b) a spider-inspired sensor image with a $20 \mathrm{~nm}$ thick platinum layer formed by a curvature of $1 \mathrm{~mm}$ radius of curvature ${ }^{[18]}$; (c) schematic diagram of working strain gating switch ${ }^{[48]}$; (d) schematic diagram of a sensor with a hole pattern. I. Before stretching, all cracks are closed. II. After stretching, the crack perpendicular to the direction of stretching opens and the other cracks close ${ }^{[49]}$; (e) the top and bottom left corners are schematic and photo based on the self-repairing CBS. The lower-right corner indicates the healing mechanism of self-healing polymers ${ }^{[51]}$; (f) cross-section illustration and SEM image of self-healing crack-based sensor. Scale bar: $1 \mu \mathrm{m}^{[51]}$. 
affected, and the crack depth was the main determinant of the sensitivity of the sensor. By further controlling the crack widening behavior, a highly stretchable (about $200 \%$ strain) and soft (elastic modulus about $5 \mathrm{MPa}$ ) silicone rubber was used instead of PUA as the substrate ${ }^{[48]}$. The conduction path of the rubber substrate is completely broken when the strain exceeds only $2 \%$. Therefore, the device acts as a strain gating switch instead of a strain sensor (Fig. 5c). Crack-based switching utilizes crack widening under tensile strain to achieve super-exponential behavior.

However, in order for CBS to achieve stable super-sensitive like arthropods, more control over crack morphology is still required. Through designing the shape of the cracked lip, the layout of the crack can be realized, thereby achieving highly sensitive detection more stably. Straight mechanical cracks formed by stress concentration of the patterned holes are a simple way to achieve controlled cracking ${ }^{[49]}$. A metal layer (first chromium, then platinum) was deposited on top of the C-polyurethane acrylate (C-PUA) ${ }^{[50]}$ with pore patterning. The rectangular samples are then strained one by one along the two grid directions to form oriented cracks. Regular cracks are induced by stress concentration between the two holes. When a tensile force is applied to the patterned crack-based sensor, cracks formed perpendicular to the tensile force will open while the parallel ones are closed (Fig. 5d).

Then, when the parameter meaning of the crack is revealed and the crack direction is adjusted, the durability of the CBS is another very important problem. In engineering, cracks are a defect that inevitably expands through external stimuli. In addition, the collection of specific excitation signals on the limited area of the sensor inevitably leads to fatigue accumulation. Normally, after several thousand cycles of the crack-based strain sensor, the sensitivity of the sensor is reduced due to fatigue accumulation. It is a worthwhile goal to have both sensitivity and durability in the crack-based strain sensor. Park et al. proposed a durable crack-based strain sensor with a Self-Healing Polymer (SHP) (Fig. 5e) ${ }^{[51]}$. The SHP achieves hydrogen bonding between amino groups $(-\mathrm{NH})$ and carbonyl groups $(-\mathrm{NCON}-)$ at temperatures above the glass transition temperature
(Fig. 5e ${ }^{[52-54]}$.The SHP are applied to the cracked Pt layer, maintaining crack gaps and geometry (Fig. 5f). The SHP allows the CBS sensor to maintain a high stability of 1 million cycles at $2 \%$ strain. The use of self-healing materials for CBS to limit the further expansion of cracks is a new solution.

\subsubsection{Polydimethylsiloxane-based crack sensor}

In addition, conventional rigid metal materials, such as metal thin foil or silicon piezoresistors, have limited flexibility, and strain sensors made with them are not as high flexible as slit sensilla of the arthropod. In order to obtain highly tensile advanced strain sensors, various strains sensing materials have been studied, such as carbon nanotube and polydimethylsiloxane $(\mathrm{PDMS})^{[35,55-58]}$, graphene and epoxy ${ }^{[59]}$. Lee et al. used silver nanoparticle (Ag-Np) film on a polydimethylsiloxane (PDMS) stamp as a strain sensing material ${ }^{[60]}$. The design principle is that tensile and compressive strains cause the opening and closing of the micron-scale crack on the silver film to realize the change of the resistance. The crack generation feature is single-step direct transfer patterning, transferring ion-based metal nano-ink from the donor substrate to the micro-structured PDMS stamp and used as sensing material and electrode (Fig. 6a). First, a mixture of the PDMS prepolymer and the curing agent were poured into a silicon mold, and an SU-8 negative photoresist pattern was prepared by a conventional photolitho-graphy process. After the PDMS stamp is formed, pressing the PDMS stamp on the donor substrate with spin-coated Ag nano-ink film for $20 \mathrm{~s}$. The PDMS stamp was removed and the silver nano-ink solution was attached to the PDMS due to cohesive failure. Finally, many cracks were created on the silver metal film when the PDMS stamp was annealed. During the extension process, the initial micro-cracks are opened and propagate through the silver $\mathrm{Np}$ networks, resulting in larger, longer micro-cracks and higher electrical resistance at higher strains (Fig. 6b). At the same time, the study proves that the strain sensor is suitable for detecting a variety of human movements, such as finger and wrist movements, as well as measuring high pressure sensitivity to low pressure. The stain sensor made with multi-layer silver 


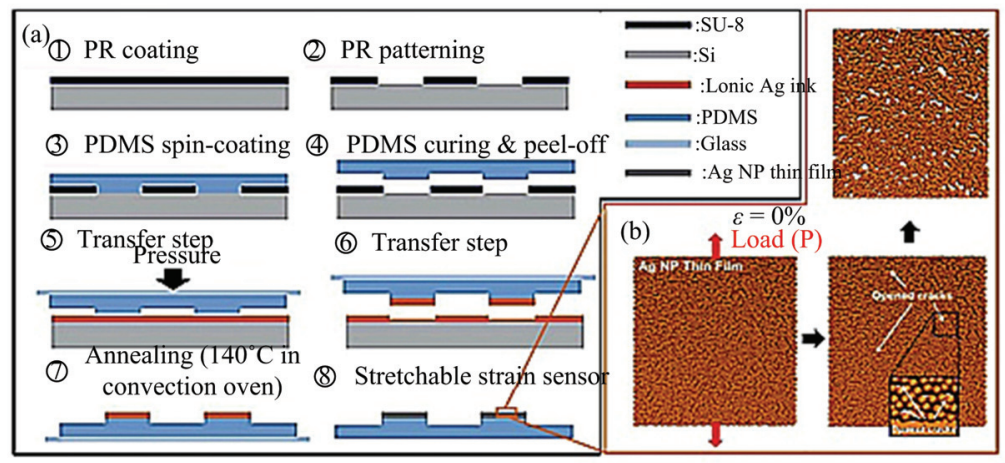

(c)

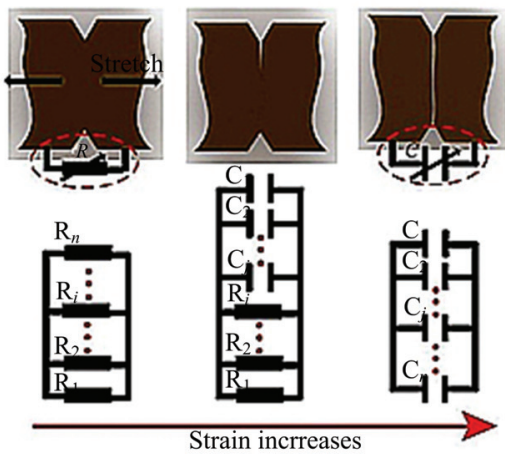

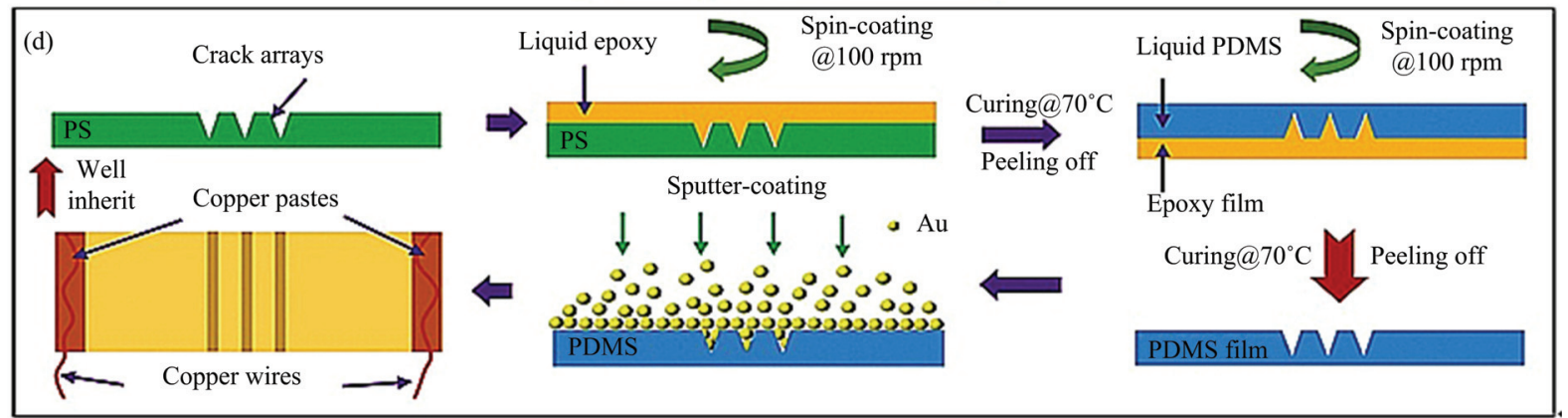

Fig. 6 Schematic diagram of crack-based sensor based on PDMS. (a) One-step direct transfer preparation process of Ag Np-based tensile strain sensor on PDMS substrate ${ }^{[60]}$; (b) molecular dynamics-based numerical simulation results of Ag-Np film stretching/relaxation process $^{[60]}$; (c) schematic diagram of the working principle of a single-crack-based strain sensor ${ }^{[1]}$; (d) the template transfer method is used to fabricate the $\mathrm{CBS}^{[69]}$.

nanoparticles synthesized has a large sensing range of about $20 \%$.

In nature, the phenomenon of cracking of materials due to moisture evaporation is widespread. The cracks created by the drying method are random. However, themethod has a simple manufacturing process and a low manufacturing cost. This way of preparing cracks is irregular compared to cracks made by stretching or bending. Wang et al. reported a crack-based strain sensor by depositing a metal film on the PDMS substrate and then pre-stretching to generate microcracks in the metal film $^{[61]}$. The metal films of the Ti layer and the Au layer were deposited on the PDMS substrate by electron-beam evaporation. A pre-stretch with $10 \%$ strain was then applied to the sample to form microcracks. Liao et al. reported a crack-based strain sensor based on a PET/vanadium dioxide $\left(\mathrm{VO}_{2}\right) / \mathrm{PDMS}$ multilayer structure fabricated using transfer technology ${ }^{[62]}$. Inspired by the biomechanical sensing of spiders, stretching strain is applied to the $\mathrm{VO}_{2}$ film on PDMS to create nanoscale cracks. Utilizing the high-temperature coefficient of resistance of $\mathrm{VO}_{2}$ materials, sensors can monitor temperature changes in real time and are promising for sensing multiple stimuli to mimic human $\operatorname{skin}^{[31,63-65]}$. In addition, for the PDMS-based CBS, the researchers used different strain materials to obtain other excellent characteristics. For example, crack-based strain sensors made of strain sensing materials multilayer $\mathrm{CNTs}^{[66]}$ and $\mathrm{Ag}$ nanowire $(\mathrm{AgNW})^{[67]}$ can accommodate a large strain range; with the application of waterproof materials $^{[68]}$, the crack-based strain sensor exhibits very stable electrical characteristics even under humidity change.

In general, the sensitivity of crack-based sensor increases as the crack density increases. However, the comparison between different density CBS has not been specifically described. The increased sensitivity due to the increased crack density also leads to the complexity of the process of processing the signal, and the sensor exhibits unstable performance. Ye et al. reported a single-crack-activated ultra-sensitive crack-based strain sensor ${ }^{[1]}$. Within the strain range of $10^{-4}$, the gauge factor of the device is beyond 108. The extremely high sensitivity of a single CBS is attributed to the transition zone of the crack. However, for multiple cracks, multi-track based sensors cannot work in the transition zone due to the complex interactions between the cracks, which essentially limits their sensitivity. Through analyzing precisely controlled single cracks rather than 
multiple cracks, the study excluded the effects of crack spacing, crack-to-crack differences, and crack-to-crack interactions, simplifying the model and facilitating a better understanding of the underlying of the crack-based sensor. A single crack-based strain sensor was fabricated by photolithography and deposition of $\mathrm{Cr}$ and $\mathrm{Au}$ in PDMS. The working principle is shown in Fig. 6c. The entire crack can be seen as a parallel between a large number of small areas. When no strain is applied, the crack is closed and the sensor exhibits electrically resistive. In this case, by slowly applying strain, the left and right portions of the crack are gradually separated, and the separated part shows capacitive. Due to the difference in local strain and the uneven distribution direction, a part of the crack is separated from another part. This is represented by the parallel connection of the resistor and the capacitor. As the strain increases, the capacitor gradually forms and the resistor gradually disappears. Until the critical strain value is reached, the two parts of the crack are completely separated and become purely capacitor. The two sides of the crack are two electrodes, and the air is a dielectric material. After the critical strain is reached, continued strain application further leads to an increase in capacitive reactance. This single crack strain process is also applicable to the process of single crack change in a conventional multi-crack-based sensor. Resistance represents the strain applied before the critical strain, and the capacitance represents the strain applied after the critical strain.

The preparation process of this crack, whether it is multi-slit or single-slit, is formed by external strains such as tensile strain or bending strain. This process causes physical damage to the PDMS, and the protection of the flexible substrate is an important part of CBS. Han et al. improved the existing flexible strain sensor through in-depth study of the slit sensilla of the scorpion $^{[69]}$. In this study, a rule-controlled microcrack array was successfully prepared on PDMS by solvent-induced swelling and dual template transfer (Fig. 6d). The template transfer method can effectively avoid any physical damage to the PDMS. The crack is generated by the cracking property of polystyrene, and the surface is uniformly and controlled by the swelling method. Then, a clear plastic epoxy $\mathrm{AB}$ glue was chosen to obtain the reverse structure, and the microcrack array was replicated using liquid PDMS. In addition, secondary control of the geometry of the fracture array can be achieved during structural transfer.

\subsubsection{Polyethylene terephthalate based crack sensor}

After the CBS has a high sensitivity and strain range, various studies have been conducted in order to make the electronic device more suitable for the human body ${ }^{[41,70-74]}$. For example, existing sensors are opaque due to material properties ${ }^{[18,75-77]}$, and fabricating sensors with high transparency and sensitivity is quite a challenging job. To solve this challenge, Lee et al. fabricated a highly transparent and sensitive mechanical CBS by depositing a transparent conductor, Indium Tin Oxide (ITO), on a trans-parent PET substrate ${ }^{[78]}$. The high transparency of the sensor comes from the inherent transparency of ITO and PET. This high transparency makes it has broad applications, including touch screens and motion detectors.

In addition to the low-light transmission of the CBS, the material of the sensor is limited to certain types due to the low adhesion between the substrate and the conductive layer. Therefore, the high adhesion of materials to substrates is a key issue for extending practical crack-based sensor systems. In the above section, due to the low adhesion between the substrate and the metal, other metals such as $\mathrm{Au}$ and $\mathrm{Ag}$ cannot be directly deposited on the PUA substrate for cracks generated. Lee et al. reported a multilayer metal film mechanical crack sensing system containing $\mathrm{Au}, \mathrm{Ag}$ and Pt. Through adding a brittle metal $\mathrm{Cr}$ layer to enhance the adhesion of the metal layer to PET $^{[79]}$. As shown in Fig. 7a, the CBS consists of four layers: a conductive metal layer ( $\mathrm{Au}, \mathrm{Ag}$ or $\mathrm{Pt}$ ), an adhesive layer ( $\mathrm{Cr})$, a brittle oxide layer (MoO3), and a bottom substrate (PET). The conductive metal layers have low resistivity and high ductility, so these metal films usually do not form cracks directly on the PET substrate. Since the Cr layer belongs to the adhesion layer between the metal films and the PET, cracks can be propagated well from the $\mathrm{Cr}$ layer to the conductive material layer. When the two layers are tightly bonded together, the crack on one side can propagate to the other. The method of adding multi-layer materials is a new way to solve the problem of low adhesion 

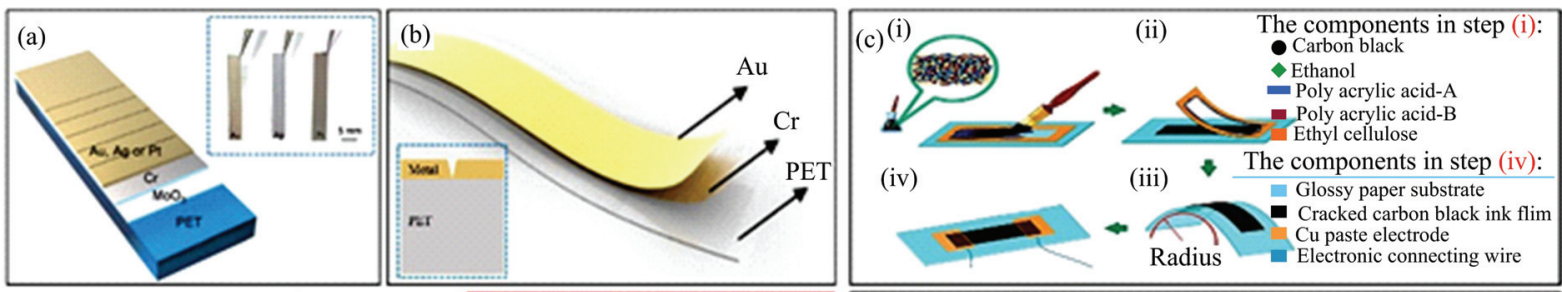

(d)
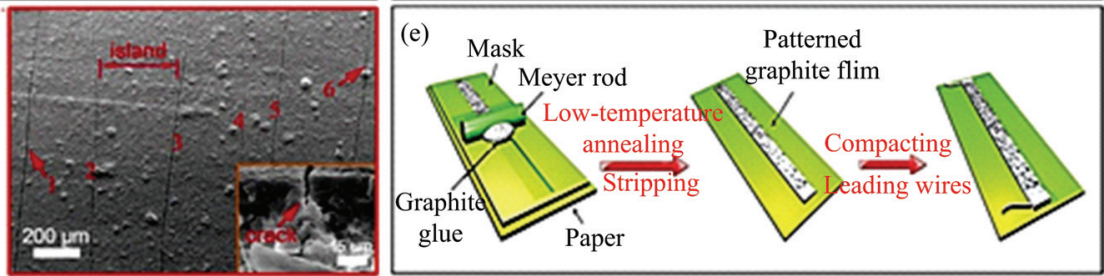

Fig. 7 Schematic diagram of CBS based on PET and paper. (a) A CBS consisting of Au, Cr, and PET. The lower-right corner is a cross-sectional image of the $\mathrm{CBS}^{[79]}$; (b) schematic diagram of CBS for multiple interlayers ${ }^{\left[{ }^{80]}\right.}$; (c) schematic diagram of the fabricating steps and composition of PMSCSS ${ }^{[84]}$; (d) upper left: When compressive strain $F$ is applied, adjacent fracture surfaces reconnect and overlap, allowing electric current to pass through the connection area. Bottom left: Schematic representation of the relaxed and stimulated state. Right: SEM image of the crack on PMSCSS $^{[84]}$; (e) schematic diagram of the fabricating steps and com-position of PPBSS ${ }^{[93]}$.

adhesion between the substrate and the conductive layer. Lee et al. reported CBS by depositing a few nanometers of chromium ( $\mathrm{Cr}$ ) and gold $(\mathrm{Au})$ on a PET film (Fig. $7 b)^{[80]}$. In addition, the relationship between the thickness of the metal layer and the characteristics of the sensor was also investigated. The improvement conditions of the sensitivity of the CBS are stated: (a) when $\mathrm{Au}$ is thin and $\mathrm{Cr}$ is thick; (b) when the ratio of $\mathrm{Au}$ is lower than the ratio of $\mathrm{Cr}$, and this also increases the transmittance and sensitivity of the sensor. Since this conclusion requires only a small amount of $\mathrm{Au}$ to achieve high sensitivity of the sensor, this further reduces fabricating costs.

\subsubsection{Paper-based crack sensor}

Wearable flexible electronic devices have significant needs in the future, which is an inevitable trend. Traditional ordinary silicon-based substrates have been unable to meet environmental requirements. More and more researchers are exploring new materials to protect the environment and reduce wasted resources. Paper-based green electronics is an emerging, environmentally friendly technology that is easy to recycle, inexpensive, and suitable for flexible electronics. Based on the above advantages, there are numerous applications for paper-based green electronic devices, such as nanogenerators ${ }^{[81]}$, supercapacitors ${ }^{[82]}$, and actuators ${ }^{[83]}$. Han et al. fabricated a unique Printable Micronscale Cracked Strain Sensor (PMSCSS) bioinspired by spi- der's crack-shaped lyriform slit sensilla ${ }^{[84]}$. The strain sensor is fabricated by a simple process preparation for coat carbon black ink on a paper substrate by screen printing (Fig. 7c). The crack was formed by mechanically bending each sample with a radius of curvature of $1 \mathrm{~mm}$. The cured ink film on the paper base is broken, and almost straight micron-scale cracks appear, cutting the film into discrete islands (Fig. 7d). The hysteresis behavior is common to strain sensors, primarily caused by the large number of connections between the conductive nanocomposites and the filler. The typical sensing nanocomposite sensors have a larger response time of $10 \mathrm{~ms}-20 \mathrm{~s}^{[85-92]}$. Typically, the response time is approximately $0.625 \mathrm{~ms}$ because the disconnecttionreconnect microscale cracks, which can change the resistance in real time, and it is inexpensive $(\sim 0.02 \$$ per device for material's cost). Liao et al. developed a new type of Printable Paper-Based Strain Sensors (PPBSSs) using graphite powder, methyl cellulose and paper ${ }^{[93]}$. Fabricating process is shown in Fig. 7e. The surface of the graphite glue forms micro/nano cracked by thermal annealing, mainly due to the evaporation of water. This is consistent with some natural crack phenomena, such as cracks on desert soils due to evaporation of water. Compared with traditional solid-state sensors, PDBSSs have the key advantages of flexibility, light weight and low price. Then, waterproof coating can be formed on the paper base by adding a waterproof material ${ }^{[94]}$. The paper-crack-based CBS can be used for conventional 
strain detection in a humid environment.

\subsubsection{Crack sensors based on other materials}

In addition to the flexible substrates described above, researchers also explored other flexible substrates and achieved superior sensing. For sensors using heat-vulnerable PET substrate, it does not have any encapsulation layer. Therefore, it is susceptible to high temperature and harsh environment. Kim et al. developed a mechanical crack-based strain sensor by alternately using a polyester film and a polyimide film as a substrate and encapsulating it with polyimide ${ }^{[95]}$. The sensor uses the polyimide (PI) instead of PET substrate. Subsequently, the sensor uses PI to perform the overall packaging. Even if exposed to different environmental liquids, humidity and temperature, it will not damage the sensor system and shorten its service life. The comprehensive performance of PI is excellent, its high temperature resistance is above $400{ }^{\circ} \mathrm{C}$, and the long-term use temperature range is $-200{ }^{\circ} \mathrm{C}-300{ }^{\circ} \mathrm{C}$. It has excellent mechanical properties and the modulus of elasticity is usually $3 \mathrm{GPa}-4 \mathrm{GPa}$. Xiao et al. developed a crack-based strain sensor based on $\mathrm{PI} /$ carbon black piezoresistive polymer composites ${ }^{[96]}$. Through periodically tearing-off treatment applying to the sensor, micron-scale cracks can be created in the composite film. In addition, the length, width and density of the crack can be controlled by a sufficient number of repeated tearing-off times. Chen et al. developed a crack-based strain sensor based on silver nanowires/graphene hybrid particles by simple coprecipitation, reduction, vacuum filtration and casting processes ${ }^{[97]}$. Due to the uneven interface, weak interfacial bonding and point-to-point conductive networks of the hybrid particles, the strain sensor successfully forms cracks and overlapping topography during pre-stretching.

Amjadi et al. fabricated a high crack-based strain sensor based on the formation of reversible microcracks in composite films ${ }^{[98]}$. The CBS can control the length, width, density and area of the crack generated through plasma-exposure and straining parameters. The main components of the strain sensor are strain-responsive membranes and flexible electrodes. After the oxygen plasma-exposure of the Ecoflex elastomer films, parallel microcracks are formed, and then through controlled strain pull them from both ends to form controlled cracks in the low-density graphite film. Parallel microcracks are uniformly initiated in graphite thin films coated on plasma-exposed elastomer films. In order to control the length, width, density and crack area, several proposed strategies are used as follows. (a) The length, width and density of the microcracks increase as the sample is further stretched; (b) the length and width of the microcracks increase as the exposure time increases; (c) parallel microcracks are created in the specified area of graphite thin films by localized plasma exposure. The interfacial adhesion prosperity of the interface between the graphite flakes and the Ecofiex film plays an important role in the high sensitivity. The microcracks are created at a specified position mainly by plasma-exposure, and then the crack is further expanded by applying tensile stress. This method can achieve the controllable parallel cracks, which provides a new idea for the development of the next CBS.

\section{Trichobothria sensilla and HLSs}

Slit sensilla and trichobothria sensilla have arrayed distributions that can locate external signals. On the other hand, the distribution of the nerves closes to the two sensilla follows the same characteristic: the nerve endings coincide with the stress concentration areas of the sensilla. In addition, both the slit sensilla and the trichobothria sensilla can be considered as efficient energy conversion systems. The in-plane and out-of-plane mechanical energy is converted into bioelectric energy, respectively. This section describes the structural characteristics of the trichobothria sensilla and the process of signal perception in more detail. Further, we present the latest HLS and summarize the general manufacturing principles of the HLS.

\subsection{Trichobothria sensilla of arthropods (spiders and scorpions)}

3.1.1 Morphology and distribution of trichobothria sensilla

Both the spider and the scorpion exoskeleton grow a hair that is ultra-sensitive to the flow of air, called the trichobothria. The trichobothria have low quality, high aspect ratio characteristics compared to other hairs, and are grown on the surface of the epidermis that is easily 
exposed to air. This also indirectly shows that the trichobothria has the advantage of being ultra-sensitive to air flow. Taking the Cupiennius salei as an example (Fig. 8a), a large amount of trichobothria is distributed on the walking legs ${ }^{[4]}$. An adult spider has about 963 trichobothria, and there are about 100 trichobothria on each leg. On the front legs of Cupiennius salei, there are about 100 trichobothria and about 108 trichobothria on the hind legs. The trichobothria are mainly distributed on the legs of the spider on metatarsus, tibia and tarsus ${ }^{[99]}$. Spider trichobothria appears in groups (Fig. 8b). The number of trichobothria consists of 2 to 24. Groups of arrays of trichobothria arranged in a way contribute more to the perception of air flow.

The spider is based on its own ultra-sensitive trichobothria sensilla to identify the external environment $^{[4]}$. The length of the trichobothria ranges from $100 \mu \mathrm{m}$ to $1400 \mu \mathrm{m}$ and can be observed directly by the naked eye. The base of the longer trichobothria is about $10 \mu \mathrm{m}$ to $15 \mu \mathrm{m}$ thick and the short hair is $5 \mu \mathrm{m}$ to $7 \mu \mathrm{m}$. The diameter of long trichobothria is about $10 \mu \mathrm{m}$ to $15 \mu \mathrm{m}$ and the short hair is $5 \mu \mathrm{m}$ to $7 \mu \mathrm{m}$. As shown in
Fig. 8b, the Cupiennius salei has longer hair lengths than other hairs, and has some tilt and bends. However, this phenomenon has not been found in other species of spiders and insects. The direction of the bend is toward the side of the long axis of legs (Fig. 8b), and curvature increases as the length of the hair increases. The trichobothria of Cupiennius salei is almost perpendicular to the epidermis, which is the preparation of the stray spider perception of air flow ${ }^{[100,101]}$. There is a large difference in the number of different types of spider trichobothria. Such as Philodromus aureoles, a small hunting spider, only have about 22 trichobothria on each walking leg ${ }^{[102]}$. Another spider that lives on web, Agelena labyrinthica, has about 25 trichobothria on each leg. Although the number of trichobothria varies among different types of spiders, they still appear in groups.

The morphology of different kinds of arthropod trichobothria is different. We discuss them with hunting spiders and web spiders ${ }^{[4]}$. Web spiders have none on the tarsi and only a few on the metatarsus, which is determined by their living environment ${ }^{[101]}$. As shown in Fig. 8c, for Cupiennius salei, the trichobothria is feathery,
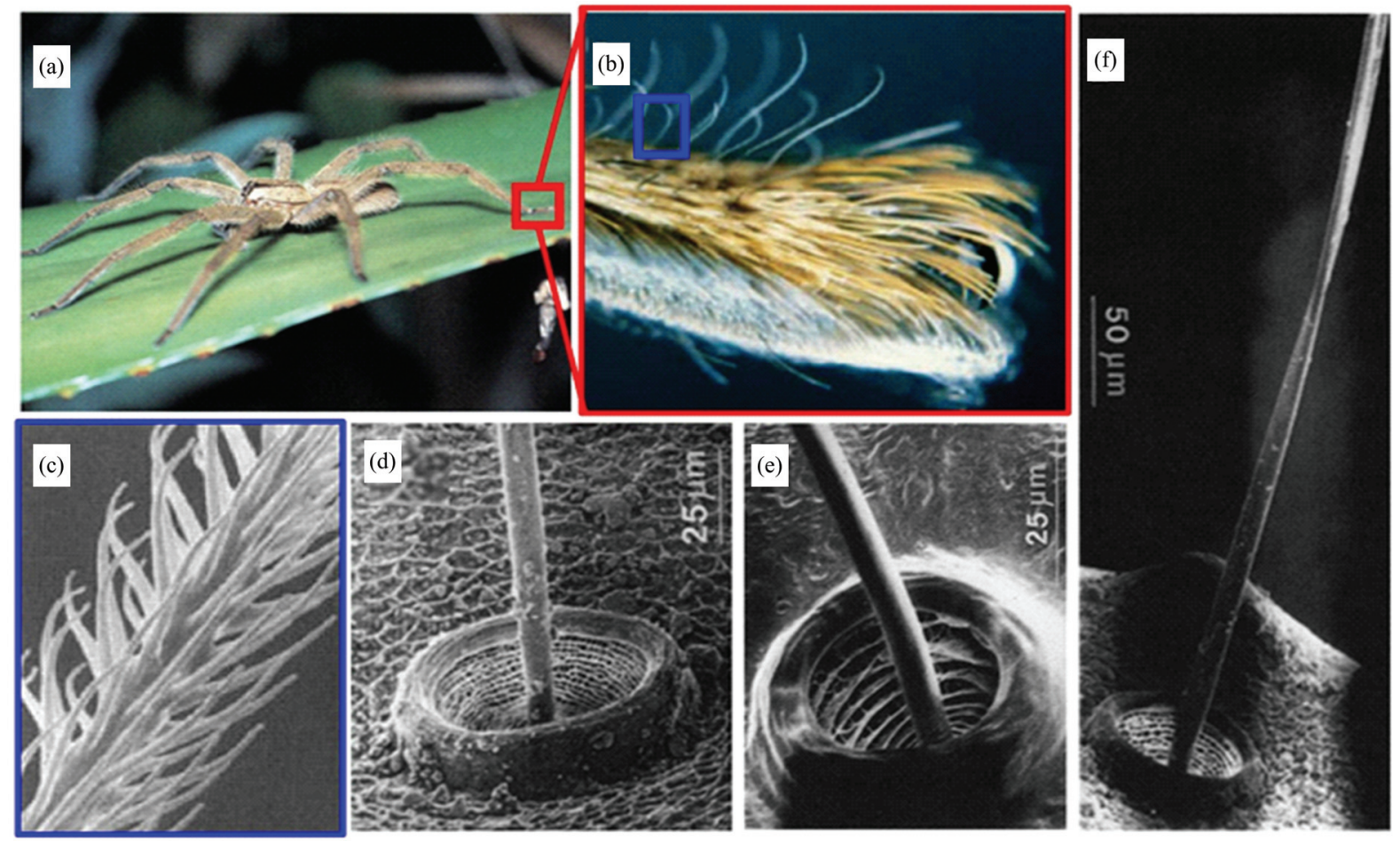

Fig. 8 The trichobothria in spider and scorpion. (a) An adult female scorpion, Cupiennius salei. The red frame represents the curved trichobothria at the end of the walking $\operatorname{leg}^{[4]}$; (b) the trichobothria at the end of the walking leg are gathered into a group and the length is lengthened in turn ${ }^{[4]}$; (c) SEM of trichobothria of Cupiennius salei is feathery ${ }^{[4]}$; (d) SEM of the cup-shaped structure of Buthus occitanus $^{[102]}$; (e) honeycomb-like structure ${ }^{[102]}$; (f) the surface of the hair shaft of the Buthus occitanus ${ }^{[102]}$. 
and this feature does not apply to all arthropods, such as the scorpion. Taking Buthus occitanus scorpion as an example ${ }^{[102]}$, the trichobothria on the surface of the scorpion are smooth (Fig. 8f). There are about 39 trichobothria on each pedipalpus. For Buthus occitanus scorpion, the number of trichobothria varies, $62 \pm 2$ on each leg ${ }^{[103]}$. The trichobothria of Buthus occitanus are characterized by a long slender hair shaft inserted into the cup-like structure of the epidermis, the cup-like structure being surrounded by a raised edge (Fig. 8d). There is a honeycomb-like structure in the cup structure (Fig. 8e). For fully developed Buthus occitanus, the diameter of the trichobothria ranges from $30 \mu \mathrm{m}$ to $55 \mu \mathrm{m}$. Unlike spiders, the scorpion trichobothria are not distributed on the walking legs, and there are not too many other hairs on the stiff epidermis. As with spiders, the trichobothria are distributed on pedipalpus that are susceptible to air flow. This array approach ensures that the trichobothria sensilla are more susceptible to air flow and easier to locate the signal source.

\subsubsection{Mechanical analysis of trichobothria sensilla}

The friction between the air and the trichobothria causes the hair rod to oscillate. As one of the most sensitive biosensors, it takes only $10^{-20} \mathrm{~J}$ for the trichobothria to generate a stimulating action potential ${ }^{[6]}$.
The key to the ultra-sensitive is that the mass of the hair rod is very light and has a high stiffness, and a small resistance to internal friction. The small resistance is achieved by "soft" suspension of the support trichobothria, which makes a slight air movement sufficient to deflect the hair. However, the actual force acting on the trichobothria is difficult to determine. The reason is that the force acting on the trichobothria does not act on one point but on the entire hair rod. In order to explore the ultra-sensitive of the trichobothria, Barth et al. performed a mechanical analysis of the trichobothria ${ }^{[4]}$. When the force of the air acted on the hair rod, we inevitably explore the thickness of the boundary layer. As shown in Fig. 9a, the flow of air forms a boundary layer on the surface of the exoskeleton ${ }^{[104]}$. The displacement of the air particles is different in the boundary layer, and the air particles located on the surface of the exoskeleton are not displaced. Outside the boundary layer, the displacement of the air particles is uniform. In the boundary layer, the velocity of the air particles is not uniform. The thickness of the boundary layer decreases as the frequency increases. The phenomenon makes shorter trichobothria is sensitive to high frequencies, while longer trichobothria is more sensitive to low frequencies.

The trichobothria located in the stratum corneum can also be represented by an inverted pendulum, which (a)

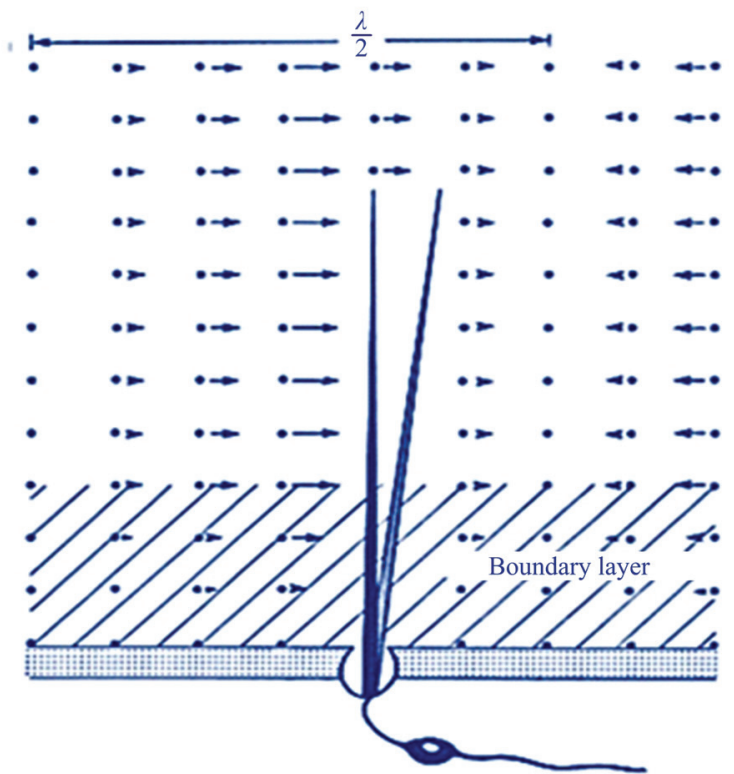

(b)

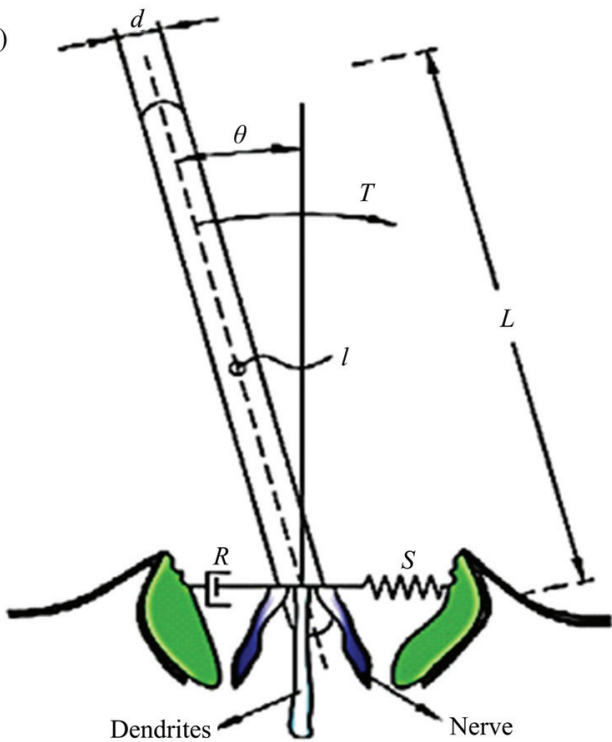

Fig. 9 Mechanical analysis of the trichobothria. (a) Air flow causes hair rod displacement. The thickness of the boundary layer depends on the frequency of the airflow ${ }^{[104]}$. (b) Schematic diagram of the mechanical model of the trichobothria ${ }^{[4]}$. 
can be thought of as a lever suspended in the air. Barth et al. simplified it as a mechanical model consisting of a spring and a damper (Fig. 9b) ${ }^{[105]}$, and gives the equation of mechanical analysis:

$$
I \ddot{\theta}=-R \dot{\theta}-S \theta+T_{D}+T_{\mathrm{VM}},
$$

where $I\left(\mathrm{Nm} \cdot \mathrm{s}^{2} \cdot \mathrm{rad}^{-1}\right)$ means the angular moment of the trichobothria, $\theta$ means angular displacement of the trichobothria, $\dot{\theta}$ means the angular velocity of the deflection and it is the first derivative of $\theta, \ddot{\theta}$ means the acceleration of the deflection and it is the second derivative of $\theta, R\left(\mathrm{Nm} \cdot \mathrm{s} \cdot \mathrm{rad}^{-1}\right)$ means the damping constant, $\mathrm{S}$ means the torsional restoring constant, $T_{\mathrm{D}}$ is the torque of the trichobothria (from the friction between the fluid and the hair rod), and $T_{\mathrm{VM}}$ (added or virtual mass) means the torque produced by the mass of the medium (accelerate with the hair rod at all times) ${ }^{[106,107]}$. For $R$ and $\mathrm{S}$, there is no specific numerical reference and must be measured experimentally ${ }^{[108,109]} . T_{\mathrm{D}}$ and $T_{\mathrm{VM}}$ are derived from the resistance generated by the motion of the medium and the integral force of the virtual mass on the full length of the hair. We use $F_{\mathrm{D}}$ and $F_{\mathrm{VM}}$ to represent the force per unit length, then $T_{\mathrm{D}}$ and $T_{\mathrm{VM}}$ are expressed as:

$$
\begin{gathered}
T_{\mathrm{D}}=\int_{0}^{L_{1}} F_{\mathrm{D}} y \mathrm{~d} y+\int_{0}^{L_{2}} F_{\mathrm{D}} L_{1} \mathrm{~d} x, \\
T_{\mathrm{VM}}=\int_{0}^{L_{1}} F_{\mathrm{VM}} y \mathrm{~d} y+\int_{0}^{L_{2}} F_{\mathrm{VM}} L_{1} \mathrm{~d} x,
\end{gathered}
$$

the full length of the hair rod is denoted by $L$, and $L_{1}$ means the length of the straight hair rod, and $L_{2}$ is the length of the curved hair rod. Barth et al. measured the mechanical frequency tuning and direction sensitivity of the trichobothria of Cupiennius salei, through a controlled variable vibrational flow field ${ }^{[101]}$. By measuring the trichobothria of the tibia, metatarsus and tarsus of Cupiennius salei, the long trichobothria are insensitive to the direction and the short bristles show a clearer preference in the direction parallel or perpendicular to the axis of the legs. The deflection angle of the trichobothria changes with the frequency of the external stimulus. The frequency of the trichobothria of Cupiennius salei is between $40 \mathrm{~Hz}$ and $600 \mathrm{~Hz}^{[4]}$. As the length of the hair increases, the optimal frequency range moves toward the low frequency. For constant stimulation, the deflection of the trichobothria increases with increasing length ${ }^{[110]}$. However, the length of the trichobothria is not the only factor that affects the deflection angle. In addition, Shimozawa and Kanou found that short trichobothria are sensitive to acceleration and long trichobothria are sensitive to velocity ${ }^{[109]}$. The feathered structure of the trichobothria of Cupiennius salei also has a greater impact on the deflection of the trichobothria. The feathered structure increases the drag forces, thereby increasing the mechanical sensitivity of the trichobothria. It prevents the movement of air particles in a small space, so the effective hair diameter in the air flow is increased. In addition, the feathered structure reduces the quality of the hair relative to its effective size. Similar to the slit sensilla, the trichobothria sensilla also has a mechanical protection mechanism. In order to prevent excessive external force damaging the trichobothria sensilla, the cup-like structure of the epidermis limits excessive deflection of the hair shaft. When the larger air flow rate causes the trichobothria to produce a greater deflection angle, the cup-like structure now limits further deflection of the hair shaft. Thereby preventing excessive deflection causes breakage of the hair shaft and destruction of the bottom neurons.

\subsubsection{Energy transformation and information recogni- tion of trichobothria sensilla}

Similar to the slit sensilla, the trichobothria sensilla are equivalent to an amplifier, transducer and filter. But in particular, the slit sensilla only absorb energy in the plane of the epidermis, while the trichobothria sensilla are energy intake in the outer space. Through the analysis of the structure of the trichobothria, we know that the trichobothria are similar to a lever, and the high-depth ratio of the hair rod concentrates the energy on the sensory cells at the bottom of the hair shaft. This process converts the mechanical energy of external air movement into electrochemical energy ${ }^{[110-112]}$. The realization of energy conversion depends on the sensory cells, which play the role of the transducer. In the last century, people have conducted detailed research on the energy conversion process of spider trichobothria ${ }^{[113-115]}$. As shown in Fig. 10a, the trichobothria is equivalent to a lever whose power arm length is much larger than re- 
sistance arm length, and the fulcrum position of lever and the sensory cells are not in the same plane. The articular membrane acts as a fulcrum for the lever, the hair shaft acts as the power arm of the lever, and the helmet structure under the membrane acts as a resistance arm for the lever. The sub-articular membrane is filled with tissue fluid, and the sensory cells are distributed under the helmet structure, and the action potential is generated by the extrusion of the helmet structure (Fig. 10b) ${ }^{[4]}$. The helmet structure plays an important role in identifying the direction of external stimuli. There is at least one sensory cell at the bottom of the helmet structure, and the number of sensory cells of different arthropods is different. For example, the number of spider sensory cell is at least three, and there are four in Cupiennius salei. The sensory cells are connected to the helmet structure through the dendrite, and the hair rod transmits the amplified signal to the helmet structure for movement by leveraging. The moving helmet structure preferentially stimulates one of the sensory cells to cause an action potential, and this difference allows the arthropod to make a direction determination of the external stimulus. Each sensory cell can feel a range of signal stimuli (Fig. 10b). Different deflection directions stimulate different sensory cells, and the more sensory cells, the stronger the direction sensitivity. At different stimulation frequencies, the trichobothria of spider has similar mechanical directionality (Fig. 10b).
The helmet structure can achieve the determination of the direction and intensity of the signal source, but it cannot filter the complex mixed signals of the external environment. The vibration frequencies of different signal source are inconsistent, which is a shortcut for determining the signal source for arthropods. By screening for specific frequencies, they can discriminate between different conditions of the outside world, and control their next behavior. Different lengths of trichobothria have different natural frequencies $(10 \mathrm{~Hz}-$ $950 \mathrm{~Hz}$ ). Barth et al. measured the natural frequency of Cupiennius salei in a calibrated oscillating flow field ${ }^{[99]}$. The different lengths of trichobothria constitute a filter, and when the natural frequency and the external frequency are the same, resonance will occur to achieve the function of signal recognition. The generation of resonance enables the hair rod to produce a large deflection angle, and the hair rod squeezes the neurons to achieve reading of external information. As shown in Fig. 10c, the lengths of the hair rods are arranged in a straight line in the leg axis to achieve measurement of the frequency. The optimum frequency range of trichobothria is between $40 \mathrm{~Hz}$ and $600 \mathrm{~Hz}$ depending on hair length. As the length of the hair rod increases, the absolute mechanical sensitivity also changes, and the arrangement of the hairs in the group provides a subdivision of the stimulus intensity and frequency range (Fig. 10c). It is worth noting that the shorter hair rod is proven to be as sensitive to velocity as the longer hair rods, but in addition
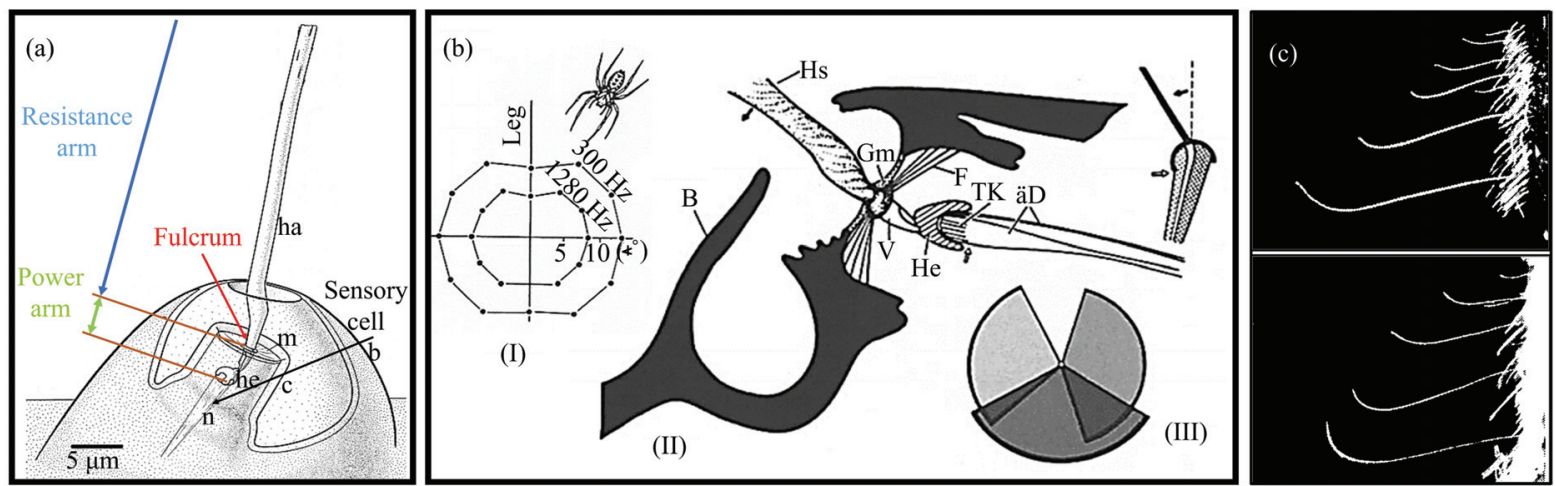

Fig. 10 (a) Schematic diagram of trichobothria similar to a lever. ha is hair shaft, $m$ is articular membrane, $b$ is bothrium, $c$ is cylinder, he is helmet, $\mathrm{n}$ is nerve processes ${ }^{[114]}$. (b) Schematic diagram of spider trichobothria on external stimulus transformation ${ }^{[4]}$. (I) The mechanical orientation at two different oscillation frequencies. (II) The nerve endings are attached to the helmet structure. Hs is hair shaft, B is cup-like structure. Gm is joint membrane. F is cuticular fibers. V is connecting part. He is helmet structure. TK is tubular body. äD is external dendrite. (III) Schematic representation of the orientation range of three sensory cells as determined by electrophysiological experiments. (c) Two groups of trichobothria on the Tibia on the walking leg of Cupiennius sale ${ }^{[99]}$. 
Table 2 Summary of hair-like flow sensors based on different fabrication sizes

\begin{tabular}{|c|c|c|c|c|c|c|c|c|c|c|}
\hline $\begin{array}{c}\text { Se- } \\
\text { rial } \\
\text { num- } \\
\text { ber }\end{array}$ & $\begin{array}{l}\text { Hair rod } \\
\text { diameter }\end{array}$ & $\begin{array}{l}\text { Hair } \\
\text { rod } \\
\text { height }\end{array}$ & $\begin{array}{l}\text { As- } \\
\text { pect } \\
\text { ratio }\end{array}$ & $\begin{array}{l}\text { Hair rod } \\
\text { material }\end{array}$ & $\begin{array}{l}\text { Bottom } \\
\text { mate- } \\
\text { rial }\end{array}$ & Method & $\begin{array}{l}\text { Working } \\
\text { principle }\end{array}$ & Performance & $\begin{array}{l}\text { Measur- } \\
\text { ing } \\
\text { object }\end{array}$ & Ref. \\
\hline 1 & $50 \mu \mathrm{m}$ & $\begin{array}{l}300 \\
\mu \mathrm{m}\end{array}$ & 6 & PDMS & PDMS & Molding & $\begin{array}{l}\text { Resistance } \\
\text { change } \rightarrow \\
\text { Electric } \\
\text { signal }\end{array}$ & $\begin{array}{c}\text { Maximum wind pressure: } \\
0.05 \mathrm{MPa}, \\
\text { Minimum wind pressure: } \\
0.08 \mathrm{MPa}, \\
\text { Response time: }<500 \mu \mathrm{s}\end{array}$ & Air flow & [115] \\
\hline 2 & $\begin{array}{c}350 / 150 \mu \mathrm{m} \\
(\mathrm{d} 1) \times 25 \mu \mathrm{m} \\
(\mathrm{d} 2) \times 10 \mu \mathrm{m} \\
(\mathrm{d} 3)\end{array}$ & $\begin{array}{c}2000 \\
\mu \mathrm{m}\end{array}$ & - & Glass fibers & CNT & $\begin{array}{l}\text { Chemical } \\
\text { vapor } \\
\text { deposi- } \\
\text { tion }\end{array}$ & $\begin{array}{l}\text { Resistance } \\
\text { change } \rightarrow \\
\text { Electric } \\
\text { signal }\end{array}$ & $\begin{array}{l}\text { Sensitivity: } 1.8 \% \text { resistance } \\
\text { change per micrometer when } \\
\text { deflected at } 500 \mu \mathrm{m} .\end{array}$ & Air flow & [119] \\
\hline 3 & $100 \mu \mathrm{m}$ & $\begin{array}{l}500 \\
\mu \mathrm{m}\end{array}$ & 5 & $\begin{array}{l}\text { Magnetic } \\
\text { nanocom- } \\
\text { posite } \\
\text { (PMDS, } \\
\text { Fe) }\end{array}$ & GMI & Molding & $\begin{array}{l}\text { Magnetic } \\
\text { field } \\
\text { change } \rightarrow \\
\text { Electric } \\
\text { signal }\end{array}$ & $\begin{array}{c}\text { In air: Resolution: } \\
0.56 \mathrm{~mm} \cdot \mathrm{s}^{-1} \\
\text { Working range: } 0 \mathrm{~mm} \cdot \mathrm{s}^{-1}- \\
190 \mathrm{~mm} \cdot \mathrm{s}^{-1}, \\
\text { Sensitivity: } 24 \mathrm{~m} \Omega(\mathrm{mm})^{-1} \cdot \mathrm{s} \\
\text { In water: Resolution: } \\
15 \mu \mathrm{m} \cdot \mathrm{s}^{-1} \\
\text { Working range: } 0 \mathrm{~mm} \cdot \mathrm{s}^{-1}- \\
7.8 \mathrm{~mm} \cdot \mathrm{s}^{-1} \\
\text { Sensitivity: } 0.9 \Omega(\mathrm{mm})^{-1} \cdot \mathrm{s}\end{array}$ & $\begin{array}{l}\text { Air flow; } \\
\text { Water } \\
\text { flow }\end{array}$ & [116] \\
\hline 4 & $1.2 \mathrm{~mm}$ & $\begin{array}{c}15 \\
\mathrm{~mm}\end{array}$ & 12.5 & PLA & $\begin{array}{l}\text { CNT } \\
\text { and } \\
\text { PDMS }\end{array}$ & $\begin{array}{c}3 \mathrm{D} \\
\text { printed }\end{array}$ & $\begin{array}{l}\text { Resistance } \\
\text { change } \rightarrow \\
\text { Electric } \\
\text { signal }\end{array}$ & $\begin{array}{c}\text { Gas working range: } 0.3 \mathrm{~m} \cdot \mathrm{s}^{-1} \\
-1.5 \mathrm{~m} \cdot \mathrm{s}^{-1}(\text { Resistance } \\
\text { changes: } 20 \%)\end{array}$ & $\begin{array}{l}\text { Air flow; } \\
\text { Water } \\
\text { flow }\end{array}$ & [120] \\
\hline 5 & $1.9 \mathrm{~mm}$ & $\begin{array}{l}220 \\
\mu \mathrm{m}\end{array}$ & 8.64 & - & $\begin{array}{l}\text { Pary- } \\
\text { lene }\end{array}$ & - & $\begin{array}{l}\text { Capaci- } \\
\text { tance } \\
\text { change } \rightarrow \\
\text { Electric } \\
\text { signal }\end{array}$ & $\begin{array}{l}\text { Working range: } 0 \mathrm{~m} \cdot \mathrm{s}^{-1}- \\
10 \mathrm{~m} \cdot \mathrm{s}^{-1} \\
\text { Resolution: } 1 \mathrm{~cm} \cdot \mathrm{s}^{-1} \\
\text { Minimum detection value: } \\
\quad 3 \mathrm{~mm} \cdot \mathrm{s}^{-1}\end{array}$ & Air flow & [121] \\
\hline 6 & $7.4 \mathrm{~mm}$ & $\begin{array}{l}0.18 \\
\mathrm{~mm}\end{array}$ & 41.11 & $\begin{array}{l}\text { Nylon } \\
\text { fibers }\end{array}$ & PDMS & $\begin{array}{l}\text { Obtained } \\
\text { from } \\
\mathrm{a} \\
\text { toothbrus } \\
\mathrm{h}\end{array}$ & $\begin{array}{l}\text { Resistance } \\
\text { change } \rightarrow \\
\text { Electric } \\
\text { signal }\end{array}$ & $\begin{array}{c}\text { Response time }: 0.7 \mathrm{~s} \\
\text { Recovery time }: 5.5 \mathrm{~s} \\
\text { Sensitivity: } 0.1 \cdot \Omega \cdot \mathrm{s} \cdot \mathrm{mm}^{-1}\end{array}$ & Air flow & [122] \\
\hline
\end{tabular}

the short hair rod is also very sensitive to acceleration. This mechanism provides a new idea for the fabrication of new speed and acceleration sensors.

\subsection{Bionic HLS}

The structure of the above arthropod can be concluded that the trichobothria is composed of a hair shaft and a sensory nerve located at the root. According to similar rules, HLS systems typically have a hair rod-like component, an elastic component, a signal conversion component, and a signal-processing component. The hair rod-like elements are connected to the elastic elements. The hair rod mainly captures the out-of-plane force, and the signal is transmitted to the signal conversion unit at the bottom by the deformation of the elastic member. The signal is then analyzed by a signal-processing component. Researchers have done a lot of researches on bionic HLS, but there are big differences in the manufacturing methods, which leads to very different performance of the HLS. According to different signal conversion methods, the HLS can be divided into piezoresistive, piezoelectric, capacitive and magnetic readout sensors. However, with the development of technology, the HLS has progressed toward a more miniaturized direction. In recent years, the diameter of the hair rod has been developed to the micro-nano level, which is closer to the size of the arthropod, and exhibits excellent flow sensing performance. At the same time, the HLS not only can detect the flow, but also the detection range extends to the sense of touch, gas perception and so on. In this section, we discuss the characteristics of HLS from the perspective of the size of the hair rod and the application of the sensor (Table 2). 


\subsubsection{Micro-size hair-like flow sensor}

In recent years, in order to improve the performance and function of flow sensors, micro-nanoscale structures are often used for the sensing layer. For example, applying nanofibers and interlocked microdome to the sensing layer increases the sensitivity and responsiveness of the sensor ${ }^{[92,114]}$. Here, the micro-scale hair-like flow sensor means that the diameter of the hair rod is less than or equal to 100 micrometers.

Chun et al. developed a multi-hair sensor that can be used for multi-mode detection like skin ${ }^{[115]}$. Through changing the stencil mask to a flexible substrate, the array of sensors and electrodes are fabricated by a simple thermal spray process of graphene nanoplates (GNPs). The micron-scale hair array on the sensor maps the electrical signals induced by the non-contact airflow to identify wind direction, angle of incidence and wind strength (Fig. 11ai and Fig. 11aii). Fig. 11aiii shows a photograph of a flexible electronic skin with a sensor and connector array. In addition, HLS with electrical response and hairy structure of different materials was studied, such as PUA and PDMS. Due to the high bendability of PDMS, under low wind pressure, it shows a greater electrical response than PUA micro hair. The HLS ultimately obtains a spatially distributed 3D profile through stress changes caused by the hair rods and estimates the direction, angle of incidence, and intensity of the applied airflow. Alfadhel et al. describe a magnetic polymer hair flow sensor that combines high resolution and low power consumption (Fig. 11biii) ${ }^{[116]}$. Micron-scale hair rods were fabricated by filling the nanocomposites in a $500 \mu \mathrm{m}$ thick template, and an array of eight holes $(800 \mu \mathrm{m}$ apart, each having a diameter of $100 \mu \mathrm{m})$ was fabricated on the template using a $\mathrm{CO}_{2}$ laser cutter. The flow of the fluid causes deflection of the magnetic nano-composite column to produce a change in the magnetic field (Fig. 11bi and Fig. 11bii). The state of the fluid is obtained by analyzing the change in the magnetic field. Then, the team was inspired by the arthropod HLS system to propose an MEMS accelerometer that was fabricated by surface micro-machining and photolithographic methods ${ }^{[117,118]}$. Maschmann et al . developed a highly integrated, highly sensitive HLS for all-round detection of low-speed airflow without the use of relatively complex MEMS technology ${ }^{[119]}$. The sensor is highly sensitive at low-speed air flow and is superior to the most other reported work. Liu et al. fabricated an HLS through the out-of-plane capillary force assisted self-fixation technology of carbon nanotubes, with a minimum diameter of $25 \mu \mathrm{m}^{[120]}$. The combination of capillary rise and self-pinning makes it possible to detect the flow sensor more sensitive to flow.

\subsubsection{Millimeter size hair-like flow sensor}

Micro-sized HLS has higher sensitivity, but the processing process is complicated and the cost is higher. In the millimeter range, researchers used innovative methods to make different highly sensitive HLS. A tensile strain flow sensor with a three-dimensional hair structure can effectively detect the out-of-plane force (Fig. 11cii) ${ }^{[120]}$. The sensor detects tensile, compressive, bending strain and distinguishes strain direction. It can be easily fabricated and used to detect small gas and fluid flows. The hair rod is directly inserted into the elastic substrate, and the entire substrate acts as a strain buffer to help absorb strain energy (Fig. 11ci). It also monitors complex flow details including flow rate, damped vibration, quasi-static force balance and flow conditions. Traditional piezoresistive or capacitive sensor structures are very fragile, limiting their use environment. The dynamic detection range of these sensors is also small. Sadeghi et al. developed a micro-hydraulic capacitive HLS to overcome these short-comings (Fig. 11dii) ${ }^{[121]}$. The sensor expands the measurement range while maintaining sensitivity. Compared to conventional capacitive sensors, the larger capacitive plate area on the back side compensates for less deflection. Compared to commonly used hot line sensors, micro-hydraulic capacitive HLS consume very little power (Fig. 11di). In addition, the system can be used normally in wet, windy or dusty environments without damage. The sensor uses nylon fiber as a mechanical signal to amplify the hair and PDMS to encapsulate the sensor. Liu et al. reported a flexible electronic HLS with multiple functions ${ }^{[122]}$. The sensor uses nylon fiber as a mechanical signal to amplify the hair and PDMS to encapsulate the sensor. The sensor can distinguish the surface roughness while sensing the air flow. In addition, the sensor also has a certain airflow direction sensing effect. 

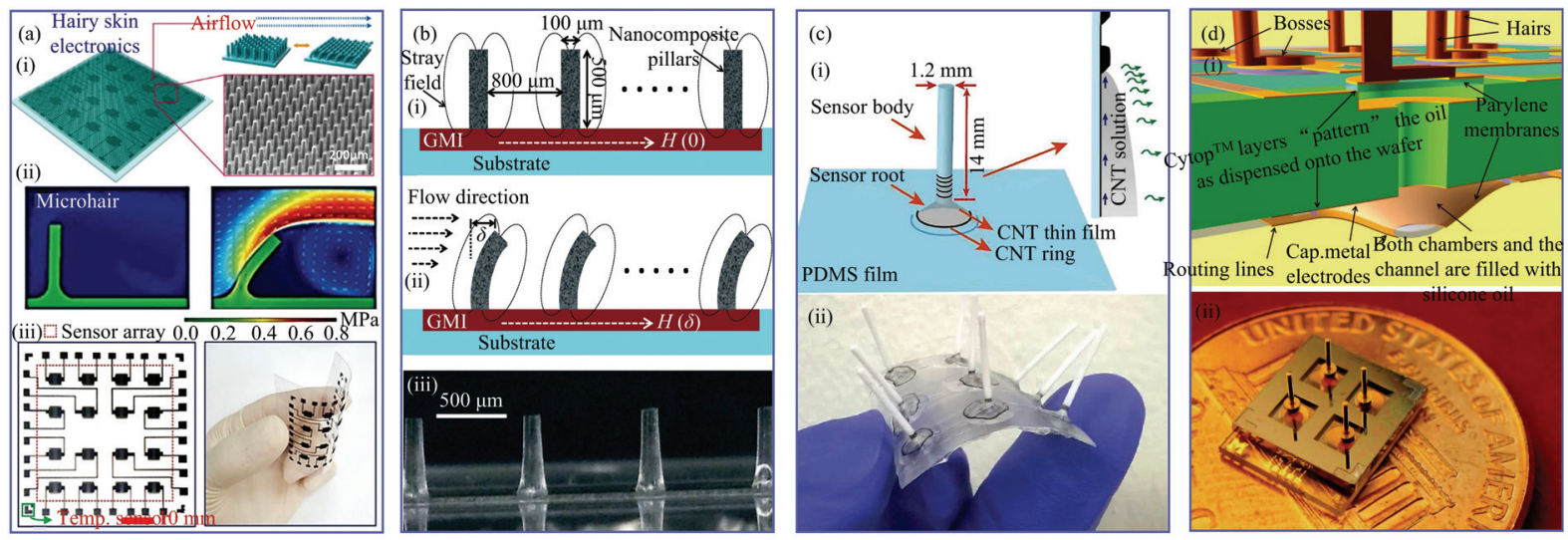

Fig. 11 Schematic diagram of the micro-scale HLS for flow detection. (a) Micro-scale HLS based on the principle of resistance change ${ }^{[115]}$ (i) Sensor array of graphene fabricated by filling micro-hairs; (ii) the simulation results when the hair rod is bent are displayed; (iii) photograph of flexible graphene nanoplatelets electronic skin. (b) Micro-scale HLS based on the principle of magnetic change ${ }^{[116]}$. (i) No fluid flow; (ii) having fluid flow; (iii) micro-scale HLS based magnetic induction. (c) Millimeter sizes HLS based on the principle of resistance chang ${ }^{[120]}$. (i) The sensing layer of the HLS is carbon nanotube; (ii) micro-scale HLS based on self-pinning principle. (d) Millimeter sizes HLS based on the principle of capacitance change ${ }^{[121]}$. (i) Micro-hydraulic structure; (ii) micro-hydraulic capacitive HLS.

\subsubsection{Other application of HLS}

The arthropod has a conical spine that can be used not only as a lever arm to promote signal transduction to achieve ultra-sensitive knowledge of flow, but also ingeniously designed to prevent mechanical damage to itself. Researchers have created high-performance force sensors through this hair structure (Table 3). Yin et al. created ultra-sensitive pressure and strain sensors through hair microparticles (Fig. 12av) ${ }^{[123]}$. Through the synthesis of zinc oxide ( $\mathrm{ZnO}$ ) particles (Fig. 12ai), it has a high aspect ratio $(>20)$ and a high density $(>150$ per particle) nanostructured spines. The tapered geometry in the spine resembles the geometry of the arthropod hair and encapsulates the zinc oxide in the PDMS (Fig. 12aii and Fig. 12aiii). The high density and spherical distribution of zinc oxide determine that mechanical stimuli can be collected from all directions. The film made of zinc oxide particles improves the sensitivity of pressure and strain sensing through electrical resistance (inter-spine contacts) and piezoresistive (spine bending) effects (Fig. 12aiv). In addition to detecting strain, the HLS can also detect the texture of the surface to achieve tactile perception. Alfadhel et al. developed a versatile biomimetic nanocomposite tactile sensor that detects shear and vertical forces, and can feel the texture of the contact surface ${ }^{[124,125]}$. This sensor detects shear and vertical forces, and the sensor can be used in air or water without any modification. Magnetic nanocomposites are composed of iron nanowires added to PDMS. When the cilia on the surface of the sensor come into contact with the surface, they deflect according to the contact surface response (Fig. 12b). This allows the magnetic nanocomposite sensor signal to be altered so that extremely fine surface features can be detected. The ability to detect multiple environmental changes with multi-modal sensing capabilities is a trend for future HLSs. Li et al. developed an ultra-sensitive multi-function sensor that combines tactile and magnetic sensitivity ${ }^{[126]}$. The core part of the sensor is an interlocking-based hair-like magnetization-induced pillar forest. It is self-assembled by exposing the carbonyl iron/silver/polydimethylsiloxane mixture layer to a magnetic field, and the manufacturing methods have the advantage of easy and rapid to produce (Fig. 12ci). The sensor also has high sensitivity to shear strain, and it was capable of discriminating shear angles less than $1^{\circ}$. The simulating stress pattern and distortion of the simplified pillar array unit at a rotation angle of $0.5 \mathrm{rad}$ is shown in Fig. 12cii. In recent years, researchers have also used hair-type sensors for specific gas detection. Han et al. were inspired by the structural features of arthropod receptors to fabricate a highly $\mathrm{H}_{2}$-reactive Janus nanofiber ${ }^{[127]}$. The bending angle of the $\mathrm{H}_{2}$-reactive Janus nanofiber array is switchable by structural deformation of the polymer fibers and asymmetrically deposited Pd overcoat (Fig. 12c). The sensor has excellent sensitivity and fast response time. The 
Table 3 Summary of hair-like flow sensors used in other fields

\begin{tabular}{|c|c|c|c|c|c|c|c|c|}
\hline $\begin{array}{c}\text { Serial } \\
\text { number }\end{array}$ & $\begin{array}{l}\text { Application } \\
\text { field }\end{array}$ & Size & Material & Method & $\begin{array}{l}\text { Working } \\
\text { principle }\end{array}$ & Performance & $\begin{array}{c}\text { Measuring } \\
\text { object }\end{array}$ & Reference \\
\hline 1 & $\begin{array}{l}\text { Tactile } \\
\text { sensor }\end{array}$ & $\begin{array}{l}\text { Diameter of } \\
\text { hair rod: } \\
100 \mu \mathrm{m} \\
\text { Length of hair } \\
\text { rod: } 500 \mu \mathrm{m}\end{array}$ & PDMS; Fe & Molding & $\begin{array}{l}\text { Magnetic field } \\
\text { change } \rightarrow \\
\text { Electric signal }\end{array}$ & $\begin{array}{l}\text { Working range: } 0 \mathrm{~mm} \cdot \mathrm{s}^{-1}- \\
7.8 \mathrm{~mm} \cdot \mathrm{s}^{-1} \\
\text { Resolution: } 15 \mu \mathrm{m} \cdot \mathrm{s}^{-1} \\
\text { Sensitivity: } 0.9 \Omega \cdot \mathrm{mm}^{-1}\end{array}$ & Force & [124] \\
\hline 2 & $\begin{array}{l}\text { Tactile } \\
\text { sensor }\end{array}$ & $\begin{array}{l}\text { Diameter of } \\
\text { hair rod: } \\
250 \mu \mathrm{m} \\
\text { Length of hair } \\
\text { rod: } 500 \mu \mathrm{m}\end{array}$ & PDMS; Fe & Molding & $\begin{array}{l}\text { Magnetic field } \\
\text { change } \rightarrow \\
\text { Electric signal }\end{array}$ & $\begin{array}{l}\text { Working range: } 0 \mathrm{~mm} \cdot \mathrm{s}^{-1}- \\
10 \mathrm{~mm} \cdot \mathrm{s}^{-1} \\
\text { Resolution: } 79 \mu \mathrm{m} \cdot \mathrm{s}^{-1} \\
\text { Sensitivity: } 0.17 \Omega \cdot \mathrm{mm}^{-1}\end{array}$ & Force & [124] \\
\hline 3 & $\begin{array}{l}\text { Tactile } \\
\text { sensor }\end{array}$ & $\begin{array}{l}\text { Diameter of } \\
\text { hair rod: } \\
1000 \mu \mathrm{m} \\
\text { Length of hair } \\
\text { rod: } 200 \mu \mathrm{m}\end{array}$ & PDMS; Fe & Molding & $\begin{array}{l}\text { Magnetic field } \\
\text { change } \rightarrow \\
\text { Electric signal }\end{array}$ & $\begin{array}{l}\text { Different results under different } \\
\text { temperature conditions, for } \\
\text { example: } \\
\text { at } 20{ }^{\circ} \mathrm{C} \text {, Working range: } 0 \mathrm{kPa} \\
-15 \mathrm{kPa} \text {, Resolution: } 1.31 \mathrm{kPa} \text {, } \\
\text { Sensitivity: } 46 \Omega \cdot(\mathrm{kPa})^{-1}\end{array}$ & Force & {$[125]$} \\
\hline 4 & $\begin{array}{l}\text { Strain sen- } \\
\quad \text { sor }\end{array}$ & $\begin{array}{c}\text { Average ta- } \\
\text { pering angle: } \\
\sim 2^{\circ}-3^{\circ} \\
\text { Aspect ratio: } \\
\sim 20-30 \\
\text { Tip size of } \\
\text { spines: } \sim 10 \mathrm{~nm} \\
-20 \mathrm{~nm}\end{array}$ & $\begin{array}{l}\mathrm{ZnO} \\
\text { PDMS }\end{array}$ & $\begin{array}{c}\text { A } \\
\text { low-temperature } \\
\text { solution process }\end{array}$ & $\begin{array}{c}\text { Resistance } \\
\text { change } \rightarrow \\
\text { Electric signal }\end{array}$ & $\begin{array}{c}\text { Strain GF: }>10^{4} \\
\text { Static-pressure: } 0.015 \mathrm{~Pa} \\
\text { Durability: }>2000 \\
\text { Response time: } \sim 7 \mathrm{~ms}\end{array}$ & $\begin{array}{l}\text { Pressure } \\
\text { strain }\end{array}$ & [123] \\
\hline 5 & $\begin{array}{l}\text { Strain } \\
\text { Sensor }\end{array}$ & $\begin{array}{l}\text { Diameter of } \\
\text { the pillar root: } \\
720 \mu \mathrm{m} \\
\text { Diameter of } \\
\text { the free end: } \\
550 \mu \mathrm{m}\end{array}$ & $\begin{array}{l}\text { CI; Ag; } \\
\text { PDMS }\end{array}$ & $\begin{array}{l}\text { Induced by a } \\
\text { magnetic field }\end{array}$ & $\begin{array}{l}\text { Resistance } \\
\text { change } \\
\rightarrow \text { Electric } \\
\text { signal }\end{array}$ & $\begin{array}{c}\text { Discriminating shear angles less } \\
\text { than } 1^{\circ} ; \\
\text { Strain sensitivity: } 1965(50-60 \% \\
\text { compressive strain); } \\
\text { Magnetic sensitivity from } 21 \mathrm{mT} \\
\text { to } 170 \mathrm{mT}\left(240 \% \mathrm{~T}^{-1}, R 2=\right. \\
0.998)\end{array}$ & $\begin{array}{c}\text { Strain } \\
\text { sagnetic }\end{array}$ & {$[126]$} \\
\hline 6 & $\begin{array}{l}\text { Gas sensing } \\
\text { sensor }\end{array}$ & $\begin{array}{l}\text { Diameter of } \\
\text { hair rod: } \\
400 \mathrm{~nm} \\
\text { Length of hair } \\
\text { rod: } 4 \mu \mathrm{m} \\
\text { Spacing dis- } \\
\text { tance: } 1.2 \mu \mathrm{m}\end{array}$ & $\begin{array}{c}\text { Nanofibers; } \\
\text { Pd }\end{array}$ & Molding & $\begin{array}{l}\text { Transmittance } \\
\text { changes } \rightarrow \\
\text { Color changes }\end{array}$ & $\begin{array}{c}\text { Response times: } 5.1 \mathrm{~s} \\
\text { Sensitivity: } 65 \%\end{array}$ & $\mathrm{H}_{2}$ & [127] \\
\hline 7 & $\begin{array}{l}\text { Acceleration } \\
\text { sensor }\end{array}$ & $\begin{array}{l}\text { Diameter of } \\
\text { hair rod: } \\
1000 \mu \mathrm{m} \\
\text { Length of hair } \\
\text { rod: } 14000 \mu \mathrm{m}\end{array}$ & Metal & - & $\begin{array}{l}\text { Resistance } \\
\text { change } \\
\rightarrow \text { Electric } \\
\text { signal }\end{array}$ & Sensitivity: $0.576 \mathrm{mV} \cdot \mathrm{g}^{-1}$ & Acceleration & [128] \\
\hline
\end{tabular}

Note: The sensitivity of the gas sensing sensor in serial number 6 is defined as the ratio between the transmittance change and the base transmittance.

sensor offers excellent sensitivity and fast response time, and enables eye-readable gas detection in a simple and economical way. Ko et al. used the piezoresistive effect to create an acceleration sensor for the working princi$\mathrm{ple}^{[128]}$. The metal rod is attached and attached to the piezoresistive film to sense the change in acceleration. When the rod receives an external force, the rod will rotate around the joint of the film to cause deformation, thereby causing a change in electrical resistance. The voltage changes due to the change in resistance, and finally the change in acceleration is recognized by the change in the voltage signal.

\section{General design methods and challenges}

\subsection{Design principles and challenges of CBS}

In recent years, many attempts and improvements have been made to achieve high sensitivity of strain sensors by breaking samples. Researchers control the material properties and environmental parameters to obtain the desired crack. Crack density, width and depth can be controlled by bending the radius of curvature and repeatedly applying pre-strain. The choice of adjusting the crack substrate can control the shape of the crack. Generally, crack creation methods can be divided into 

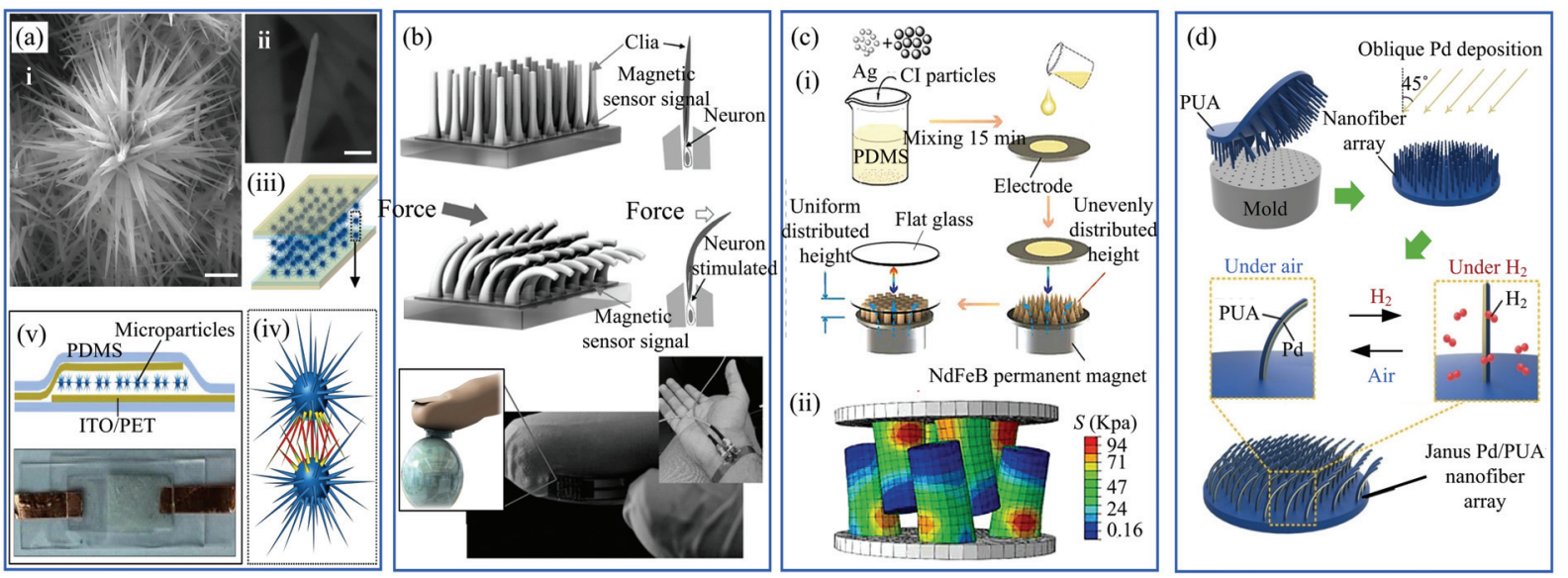

Fig. 12 Hair-like flow sensor applications in other fields. (a) A hair-like flow sensor for use in the field of pressure and strain ${ }^{[123]}$. (i) SEM image of zinc oxide particles nanostructure. Scale bar is $1 \mu \mathrm{m}$; (ii) SEM image of the tip of the spine. Scale bar is $100 \mathrm{~nm}$; (iii) a sensor made of zinc oxide sandwiched between two electrodes; (iv) mechanical stimulation-induced interaction; (v) the layered structure and photograph of the zinc oxide sensor. (b) A hair-like flow sensor for use in the field of tactile perception ${ }^{[124]}$. (c) An interlocking-based hair-like magnetization-induced pillar forests device ${ }^{[126]}$. (i) The manufacturing process of hair-like magnetization-induced pillar forest; (ii) the stress distribution of the simplifed pillar array unit at a rotation angle of $0.5 \mathrm{rad}$. (d) Schematic diagram of the manufacturing process and principle of the $\mathrm{H}_{2}$-reactive Janus nanofiber array ${ }^{[127]}$.

the following types: pre-stretching, pre-bending, template transfer, plasma-exposure, annealing and drying, etc. Crack creation methods are different for different CBS, but these methods are also regularly ruled. For example, for the way in which cracks are generated based on bending, the main advantage is the ability to produce uniform, controllable transverse through cracks. The method of stretching is similar to the method of bending. The conductive layer is broken by stretching both ends of the sensor to generate cracks. The CBS fabricated by the stretching method can achieve higher sensitivity and micro-variable detection. In addition, some new methods of creating cracks can be applied to the preparation of CBS in the future. For example, Mondal et al. created a parallel crack pattern by a film thickness gradient formed under the gravity flow of the colloidal dispersion on the inclined substrate ${ }^{[129]}$.

In general, the more the number of cracks, the more sensitive the CBS, but this may not be completely correct. Analysis from a single slit of the CBS reveals that a single-slit structure can achieve higher sensitivity than a multi-slit structure ${ }^{[1]}$. However, compared to a multi-slit structure, a single-slit structure cannot have a high strain range, which is a disadvantage. In the future, the CBS will make ultra-high sensitivity, and large strain range coexist by more fine-grained control of a single slit structure and multiple crack arrays. Fabricating ultra-sensitive strain sensors typically require a two-part structure: the elastomeric substrate provides stretchability and the brittle conductive layer provides a fracture geometry under tension. In making the CBS, a transition layer is typically introduced to achieve a tighter bond between the elastomeric substrate and the brittle conductive layer, such as $\mathrm{Cr}$ and Ti. Many strain sensors are based on this principle to create a slit structure to increase sensitivity.

However, crack-based strain sensors have many problems to solve. (a) At the time of crack generation, the crack generation of the CBS is not completely controllable, and only a certain density of cracks can be generated in a rough region. Moreover, the generated crack density and width cannot be consistent, and can only be controlled within a certain range, which has a great influence on the performance of the sensor. In other words, after using the same method, each CBS performance parameter is still very different compared to the existing strain gauge, such as initial resistance, GF and fatigue resistance. However, the length of the crack in the CBS can be controlled by the width of the strain responsive material layer. The premise requires that the crack penetrates completely through the width of the sensing strain layer, that is, the length of the crack is the width of the sensing strain layer. Also, the depth of the 
crack in the CBS can be controlled by the thickness of the strain responsive material layer. The premise requires that the crack completely penetrates the thickness of the sensing strain layer, that is, the depth of the crack is the thickness of the sensing strain layer. The controllable need for crack length and depth is determined by the width and thickness of the strained layer, otherwise the width and thickness of the resulting crack can only be guaranteed to have approximately the same width and thickness. (b) After the crack is generated, the crack will further expand as the strain is cyclically loaded. The expansion of the crack in the engineering will invalidate the crack of the material. The crack structure in the CBS greatly increases the sensitivity of the strain sensor, but it also causes the sensor accuracy to decrease as the crack propagates. (c) The strain sensors with cracked film structures have higher sensitivity, but the sensors show lower stretch and have a highly nonlinear response ${ }^{[74,98]}$.

In response to such problems, we need to learn more from biology. For crack propagation and controllable problems, we can refer to the bio-fracture-prevention strategy and perceptual sensing structure in the previous section to prevent or limit crack propagation and optimize the layout of cracks.

\subsection{Design principles and challenges of HLS}

In the arthropod, when the mane feels the change of air velocity, it mainly depends on the hair rod and the hair cells at the bottom. Both serve as the role of signal collection and signal conversion. There are also two similar parts in the HLS, which are the hair rod part and the sensing part, respectively. The method of fabricating the hair rod portion is generally a template method. Existing manufacturing methods are difficult to replicate completely relative to the micro-scale hair rods of arthropods. For micron-sized hair rods, researchers generally indirectly fabricate by etching template. First, the pore structure having a diameter of micron is etched on the base template, and then the liquid material is filled with the pore structure. Then, after the liquid material is solidified, the template is removed to form a columnar hair rod. However, the drawback of this method is the inability to form a large depth ratio of the hair rod structure. This is a drawback because the greater the depth ratio of the hair rod, the greater the ability to measure the external signal. In centimeter-scale manufacturing, researchers usually use off-the-shelf hairy structures, such as nylon fibers ${ }^{[122]}$. In addition, printing manufacturing represented by $3 \mathrm{D}$ printing is also an emerging technology for developing hairy structures ${ }^{[120]}$. The elastic modulus of the hair rod structure in the HLS is often the main parameter determining the function of the sensor. A hair rod structure having a small modulus of elasticity allows the sensor to avoid damage to the hair rod and the bottom elastic member due to excessive external force. In addition to this, the wool structure can exhibit softness, causing it to bend, and the sensor can complete the process of tactile perception ${ }^{[122,125]}$.

The bottom sensing part is generally a combination of elastic material and sensing material. The elastic material is generally a low elastic modulus material such as PDMS or PUA. In addition, a miniature spring can also be cited as an elastic material. The role of the elastic material is mainly to provide deformation information for the sensing material, and the sensing material converts the deformation information into an electrical signal. The sensing principle of the HLS can be divided into: piezoresistive, piezoelectric, inductive, capacitive, photoelectric, and fiber optic ${ }^{[130]}$. However, the HLS still faces some problems. (a) The exploration of the biological mechanism of the HLS is still not deep. The signal coding method of arthropod trichobothria under multi-signal excitation cannot be fully understood. There is also no in-depth understanding of the hair cell nerve conduction mechanism and the hair rod frequency screening mechanism. (b) The existing HLS does not utilize the array effect of the trichobothria, and the response of the single HLS to the direction of air flow is also unsatisfactory. Most of the existing HLS mainly locate the external signal source through the sequential arrangement of multiple hair-like structures, but this will result in voluntary waste and cost increase. We can achieve high-efficiency, low-cost signal source positioning by mimicking the arrangement of trichobothria on the surface of arthropods. (c) In the HLS, a large range and high sensitivity are still a contradiction. The HLS requires a large swing of the hair rod under a small excitation, but a large swing also makes it easy for the hair rod to reach the maximum range critical point. Although the sensitivity is increased, its range is limited. 
We need to continue to find more suitable materials and excellent signal conversion methods in the sensing part to achieve a large range and high-sensitivity coexistence.

\section{Applications}

With the rapid development of human health detection and intelligent robots, wearable electronic devices have shown great market prospects. Researchers have extensively explored the large variable, high sensitivity, and fast response of flexible wearable electronic sensors. The CBS has unique advantages in terms of light weight and portability, excellent electrical performance and high integration, making it one of the most concerned electrical sensors. The CBS has high sensitivity and large strain range, and it can be flexibly strained. Therefore, it is often used in wearable strain devices, such as the personalized health monitoring $^{[131,132]}$, human motion detection ${ }^{[35,133]}$, soft robot$\operatorname{ics}^{[134,135]}$, human interface ${ }^{[136]}$. Similarly, the HLS has received widespread attention and development due to their high sensitivity, high resolution, and fine frequency response. The HLS performs excellently in terms of flow detection, surface texture detection, etc.

\subsection{Application of CBS}

The CBS can be used as a wearable sensor to monitor subtle movements of human muscles or joints, such as the bending state of the fingers, physiological pulse, and walking motion. Due to its small strain sensitivity and high flexibility, the CBS can be comfortably mounted on human skin.

Fig. 13 shows that various motion states of the human body can be measured by CBS. The CBS can distinguish between signal and background noise while capturing external sound. The sensor is placed in the throat of the volunteer, and it captures clearly identifiable signals with excellent immunity to interference and high sensitivity. The anti-jamming speech recognition system built by the crack-based strain sensor will play an important role in smart home, portable electronic equipment and even military security. The CBS can detect the heart rate of the human body in real time. The existing photoelectric heart rate meter measures the heart rate according to the absorbance of blood, and the addition of the CBS can optimize the heart rate calcula- tion algorithm, which greatly promotes the accuracy of the wearable device data. The CBS is expected to advance the development of smart wearable devices, such as more accurate acquisition of the body's exercise state and sleep state. The CBS can measure the heartbeat of different movement states of the human body. For example, the heartbeat state of the human body can be collected in real time and under two different conditions after running. The sensor records the signal and provides important cardiac physiology information for the medical field, such as the diastolic and contractile movements of the heart. The CBS is an inexpensive flexible strain sensor that detects the movement of the human leg. It also mimics human skin for accurate pressure, humidity and temperature. The sensor can be used for sensing detection on the prosthesis and enriching the function of the prosthesis. At the same time, robots can be provided with artificial skin similar to human skin for various tests, so that the robot can sense the stimulation of the external environment like a human being. The CBS detects motion around the human eye. Through the waterproof material or the waterproof package, the CBS can work normally in the sweat environment. When the eyes are closed, the skin is pulled and the resistance of the sensor increases. When the eyes opened again, the skin is slack and the resistance returns to its original value. The sensor maintains high sensitivity even in environments with a lot of sweat and oil. Therefore, the CBS plays an important role in stress detection in complex environments such as wet and underwater environments. The CBS responds to finger movements, which provides an intuitive reference for potential applications of robotics. Secure the sensor to finger, bend and release at different angles. A very pronounced change in resistance was observed, and it was found to be proportional to the mechanical. In the future, it can play an important role in human-computer interaction and intelligent robot finger motion detection. The CBS is capable of detecting the movement state of the arm and the relaxed state of the muscle. The movement of the arm can be sensed by attaching a CBS to the forearm, and the tension and relaxation of the muscle can also be detected. In addition to the application to the joints of the human body, it can also be applied to the changes in the specific shape of the human body. Since 


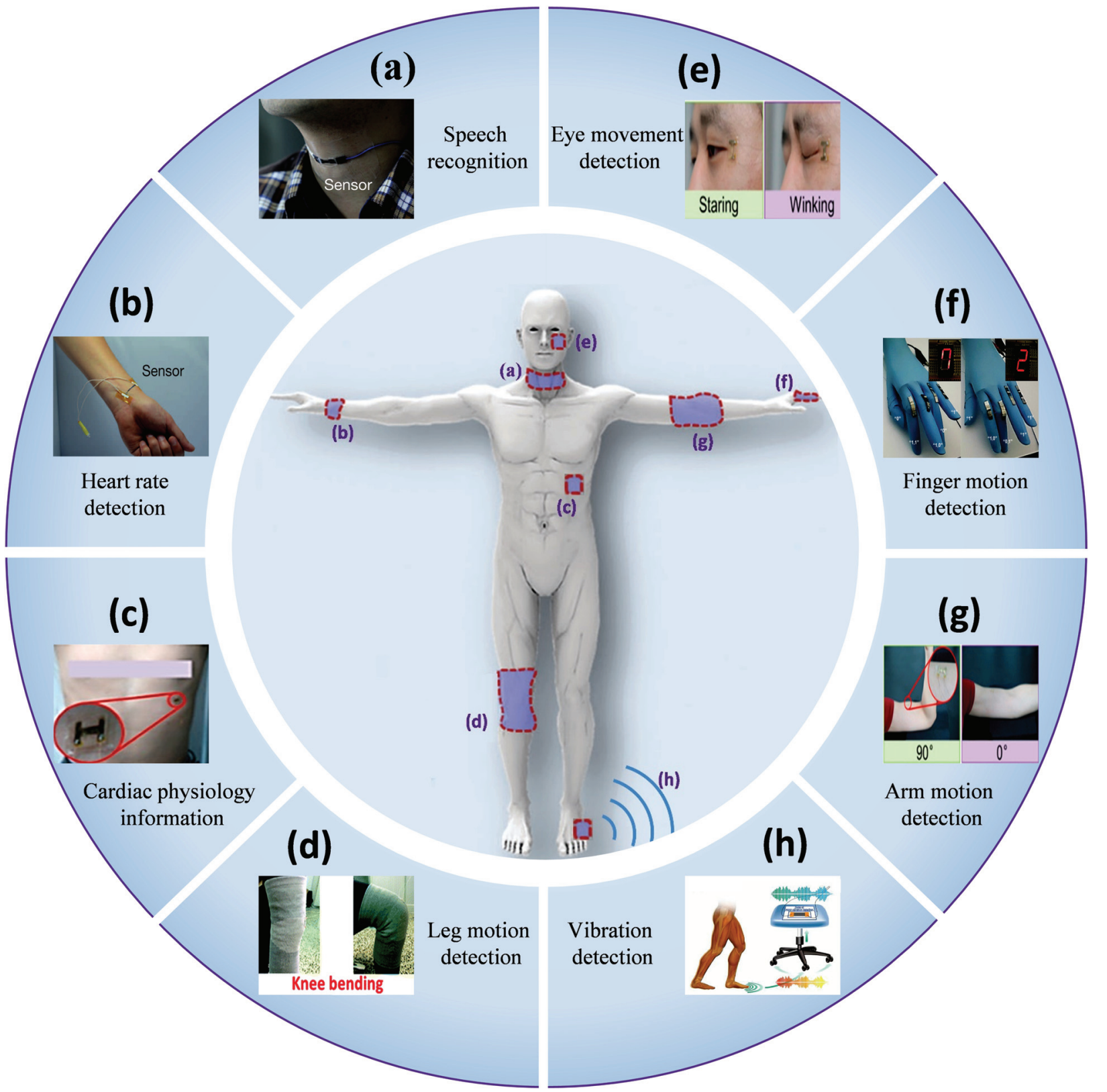

Fig. 13 Demonstration of CBS application for detecting human motion and health ${ }^{[66]}$. The picture of the middle mannequin copyright comes from the Royal Society of Chemistry 2018. (a) Distinguishing between signal and background noise ${ }^{[18]}$; (b) heart rate and wrist movements $^{[18]}$; (c) heartbeat state of the human body ${ }^{[61]}$; (d) leg movement of the human body ${ }^{[66]}$; (e) eye movement ${ }^{[61]}$; (f) finger bending degree of the human body and the recognition of the gesture ${ }^{[48]}$; (g) the state of the human $\operatorname{arm}^{[61]}$; (h) walking state of the human body ${ }^{[93]}$.

the CBS has an advantage in response time and sensitivity, it can be used to detect vibration of human motion. It is very sensitive to passive detection of vibrations caused by human motion. During the walking and jumping process, the sensor can clearly detect different resistance changes. Through an array of CBS, the moving objects can also be positioned. There are potential applications in the field of vibration detection and location recognition in the future.

\subsection{Application of HLS}

The HLS provides precise sensing of flow and mechanical signals. In addition to flow sensing, the HLS can extend and develop other types of sensors, such as tactile sensors, acceleration sensors, and gas sensing sensors, according to its working mechanism. In future, the HLS may help intelligent robots detect unknown and complex terrain. The HLS can be used as a quality measuring tool with its high aspect ratio cantilever beam 
to achieve accurate detection of the quality of tiny objects. The HLS itself can be seen as a high-performance wind energy conversion device that can convert between wind energy and electric energy. This allows the HLS to convert wind power at ultra-low wind speeds and can be deployed in low wind speed areas to alleviate energy shortages. In addition, the development of the HLS provides the sensory ability of the electronic skin and the flexible skin of the robot to the spatial flow information that the CBS does not have, opening the way for the next generation of the scalable sensor. It also can help the unmanned technology and underwater robot navigation technology through the HLS. With the advent of $5 \mathrm{G}$ networks, the advantages of the HLS are growing. Mainly reflected in the unmanned logistics, unmanned car driving, in which the HLS mainly acts as a highly sensitive speed sensor and acceleration sensor.

\section{Conclusion}

This review firstly has an overview of the development of CBSs and HLSs inspired by arthropods' mechanical sensilla. In order to better understand the biological strategies of slit sensilla and trichobothria sensilla, this review describes their distribution, morphology, mechanical analysis, energy transformation and information recognition by taking spiders and scorpions as examples. The researchers produced CBSs and HLSs with high sensitivity by imitating these two sensilla. The CBSs are mainly used for strain detection, and HLSs are mainly used for flow detection, corresponding to the biological model. However, these two sensors have also been applied to other fields, such as tactile perception and acceleration, which will be a development trend in the future.

The CBSs have rapidly developed in recent years, and its sensitivity has also been significantly improved (GF up to 108), mainly due to the significant change in the resistance of the circuit caused by crack opening and closing. The cracks in CBS can be manufactured mainly by pre-stretching, pre-bending, template transfer, plasma-exposure, annealing and drying. Although the CBSs have made great progress in recent years, it is still in the laboratory stage. In spite of great progress in recent years, CBSs are still in the experimental stage, which is because that their incomplete controllability makes it impossible to unify the sensor. In addition, the sensing layer and flexible strain layer of the sensor itself are relatively fragile and have poor adaptability to the environment. In the future, cracks in the CBSs need to be further refined on their width and length, and it is also important to check whether cracks penetrate the strain player. In addition, researchers need to further simulate arthropod crack sensors to create more stable CBSs.

In recent years, with the further development of excellent structure and new materials, HLSs also have made great progress, making it easier for sensors to pick up external mechanical signals and convert them into electrical signals. At present, the main ways of converting into electrical signals can be divided into piezoresistive, piezoelectric, inductive, capacitive, photoelectric, and fiber optic. However, some problems still need to be resolved for the sensor such as large range and high sensitivity, which are still a contradiction. As material costs decrease and manufacturing technology becomes increasingly mature, HLSs are bound to develop rapidly. To sum up, nature provides us with excellent models, and we need to learn from the processing strategies of biological models to further improve the sensitivity and reliability of the sensors. In the future, CBSs and HLSs will inevitably play an increasingly important role in wearable smart devices, robot mechanical quantity sensing systems and other fields.

\section{Acknowledgment}

Zhang $\mathrm{C} \mathrm{C}$ and Zhang $\mathrm{J}$ Q contributed equally to this work. This work was financially supported by the National Key Research and Development Program of China (No. 2018YFA0703300), the National Natural Science Foundation of China (Nos. 51835006, 51675220,51875244 and U19A20103), Joint fund of the Ministry of education for equipment research (6141A02022131), the JLU Science and Technology Innovative Research Team (No. 2017TD-04), the Natural Science Foundation of Jilin Province of China (No. 20200201232JC), the Science and technology research project of education department of Jilin province (No. 20190141), the Joint Construction Project of Jilin University and Jilin Province (No. SF2017-3-4), the Opening Project of the Key Laboratory of Bionic Engineering 
(Ministry of Education), Jilin University (K201903), and Fundamental Research Funds for the Central Universities.

Open Access This article is licensed under a Creative Commons Attribution 4.0 International License, which permits use, sharing, adaptation, distribution and reproduction in any medium or format, as long as you give appropriate credit to the original author(s) and the source, provide a link to the Creative Commons licence, and indicate if changes were made.

The images or other third party material in this article are included in the article's Creative Commons licence, unless indicated otherwise in a credit line to the material. If material is not included in the article's Creative Commons licence and your intended use is not permitted by statutory regulation or exceeds the permitted use, you will need to obtain permission directly from the copyright holder.

To view a copy of this licence, visit http://creativecommons.org/licenses/by/4.0/.

\section{References}

[1] Ye J L, Yang T T, Zhang Y F, Lin L. Single-crack-activated ultrasensitive impedance strain sensor. Advanced Materials Interfaces, 2018, 5, 1800616.

[2] Zhang C C, Chen D B, Niu S C, Zhang J Q, Meng X C, Liu L P, Sun T, Wen S F, Zhou Y, Shi Y S, Han Z W, Ren L Q. High-aspect-ratio deflection transducers inspired by the ultra-sensitive cantilever configuration of scorpion trichobothria. Journal of Materials Chemistry C, 2020, 8, 6093-6101.

[3] Kroetz G H, Eickhoff M H, Moeller H. Silicon compatible materials for harsh environment sensors. Sensors and Actuators A: Physical, 1999, 74, 182-189.

[4] Barth F G. A Spider's World. Springer, Berlin Heidelberg, Germany, 2002.

[5] Barth F G. Spider senses - Technical perfection and biology. Zoology, 2002, 105, 271-285.

[6] Fratzl P, Barth F G. Biomaterial systems for mechanosensing and actuation. Nature, 2009, 462, 442-448.

[7] Barth F G, Lirera W. Ein atlas der spaltsinnesorgane von Cupiennius salei keys. Chelicerata (Araneae). Zeitschrift Für Morphologie Der Tiere, 1970, 68, 343-336.

[8] Young S L, Chyasnavichyus M, Barth F G, Zlotnikov I, Politi Y, Tsukruk V V. Micromechanical properties of strain-sensitive lyriform organs of a wandering spider $(\mathrm{Cu}$ - piennius salei). Acta Biomaterialia, 2016, 41, 40-51.

[9] McConney M E, Schaber C F, Julian M D, Barth F G, Tsukruk V V. Viscoelastic nanoscale properties of cuticle contribute to the high-pass properties of spider vibration receptor (Cupiennius salei Keys). Journal of the Royal Society Interface, 2007, 4, 1135-1143.

[10] Barth F G, Wadepuhl M. Slit sense organs on the scorpion leg (Androctonus australis L. Buthidae). Journal of Morphology, 1975, 145, 209-227.

[11] Brownell P, Farley R D. Detection of vibrations in sand by tarsal sense organs of the nocturnal scorpion, Paruroctonus mesaensis. Journal of comparative Physiology A - Neuroethology Sensory Neural and Behavioral Physiology, 1979, 131, 23-30.

[12] Stürzl W, Kempter R, Van Hemmen J L. Theory of arachnid prey localization. Physical Review Letters, 2000, 84, 5668-5671.

[13] Adams S V, Wennekers T, Bugmann G, Denham S, Culverhouse P F. Application of arachnid prey localisation theory for a robot sensorimotor controller. Neurocomputing, 2011, 74, 3335-3342.

[14] Wang K J, Zhang J Q, Song H L, Fang Y Q, Wang X L, Chen D B, Liu L P, Niu S C, Yao Z W, Han Z W, Ren L Q. Highly efficient mechanoelectrical energy conversion based on the near-tip stress field of an antifracture slit observed in scorpions. Advanced Functional Materials, 2019, 29, 1807693.

[15] Barth F G, Stagl J. The slit sense organs of arachnids. Zoomorphologie, 2005, 86, 1-23.

[16] Fratzl P. Applied physics the virtues of tiling. Nature, 2014, 516, 178-179.

[17] Fratzl P, Kolednik O, Fischer F D, Dean M N. The mechanics of tessellations-bioinspired strategies for fracture resistance. Chemical Society Reviews, 2016, 45, 252-267.

[18] Kang D, Pikhitsa P V, Choi Y W, Lee C, Shin S S, Piao L, Park B, Suh K Y, Kim T I, Choi M. Ultrasensitive mechanical crack-based sensor inspired by the spider sensory system. Nature, 2014, 516, 222-226.

[19] Höß1 B, Böhm H J, Schaber C F, Rammerstorfer F G, Barth F G. Finite element modeling of arachnid slit sensilla: II. Actual lyriform organs and the face deformations of the individual slits. Journal of comparative Physiology A - Neuroethology Sensory Neural and Behavioral Physiology, 2009, 195, 881-894.

[20] Livne A, Bouchbinder E, Svetlizky I, Fineberg J. The near-tip fields of fast cracks. Science, 2010, 327, 1359-1363.

[21] French A S, Torkkeli P H, Seyfarth E A. From stress and 
strain to spikes: Mechanotransduction in spider slit sensilla. Journal of Comparative Physiology A - Neuroethology Sensory Neural and Behavioral Physiology, 2002, 188, 739-752.

[22] Hoger U, Seyfarth E A. Structural correlates of mechanosensory transduction and adaptation in identified neurons of spider slit sensilla. Journal of Comparative Physiology A - Neuroethology Sensory Neural and Behavioral Physiology, 2001, 187, 727-736.

[23] Fabian R, Seyfarth E A. Acetylcholine and histamine are transmitter candidates in identifiable mechanosensitive neurons of the spider Cupiennius salei: An immunocytochemical study. Cell and Tissue Research, 1997, 287, 413-423.

[24] Juusola M, Seyfarth E A, French A S. Sodium-dependent receptor current in a new mechanoreceptor preparation. Journal of Neurophysiology, 1994, 72, 3026-3028.

[25] Höger U, Torkkeli P H, Seyfarth E A, French A S. Ionic selectivity of mechanically activated channels in spider mechanoreceptor neurons. Journal of Neurophysiology, 1997, 78, 2079-2085.

[26] Seyfarth E A, French A S. Intracellular characterization of identified sensory cells in a new spider mechanoreceptor preparation. Journal of Neurophysiology, 1994, 71, 1422-1427.

[27] Kim D H, Lu N S, Ma R, Kim Y S, Kim R H, Wang S D, Wu J, Won S M, Tao H, Islam A, Yu K J, Kim T I, Chowdhury R, Ying M, Xu L Z, Li M, Chung H J, Keum H, McCormick M, Liu P, Zhang Y W, Omenetto F G, Huang Y G, Coleman T, Rogers J A. Epidermal electronics. Science, 333, 838-843.

[28] Takei K, Takahashi T, Ho J C, Ko H, Gillies A G, Leu P W, Fearing R S, Javey A. Nanowire active-matrix circuitry for low-voltage macroscale artificial skin. Nature Materials, 2010, 9, 821-826.

[29] Kim D H, Lu N S, Huang Y G, Rogers J A. Materials for stretchable electronics in bioinspired and biointegrated devices. MRS Bulletin, 2012, 37, 226-235.

[30] Kaltenbrunner M, Sekitani T, Reeder J, Yokota T, Kuribara K, Tokuhara T, Drack M, Schwödiauer R, Graz I, Bauer-Gogonea S, Bauer S, Someya T. An ultra-lightweight design for imperceptible plastic electronics. Nature, 2013, 499, 458-463.

[31] Chortos A, Lim J, To J W F, Vosgueritchian M, Dusseault T J, Kim T H, Hwang S, Bao Z. Highly stretchable transistors using a microcracked organic semiconductor. Advanced Materials, 2014, 26, 4253-4259.

[32] Mannsfeld S C B, Tee B C K, Stoltenberg R M, Chen C V H
H, Barman S, Muir B V O, Sokolov A N, Reese C, Bao Z. Highly sensitive flexible pressure sensors with microstructured rubber dielectric layers. Nature Materials, 2010, 9, 859-864.

[33] Wang Z L. Self-powered nanosensors and nanosystems. Advanced Materials, 2012, 24, 280-285.

[34] Wu W Z, Wen X N, Wang Z L. Taxel-addressable matrix of vertical-nanowire piezotronic transistors for active and adaptive tactile imaging. Science, 2013, 340, 952-957.

[35] Yamada T, Hayamizu Y, Yamamoto Y, Yomogida Y, Izadi-Najafabadi A, Futaba D N, Hata K. A stretchable carbon nanotube strain sensor for human-motion detection. Nature Nanotechnology, 2011, 6, 296-301.

[36] Yeom C, Chen K, Kiriya D, Yu Z B, Cho G, Javey A. Large-area compliant tactile sensors using printed carbon nanotube active-matrix backplanes. Advanced Materials, 2015, 27, 1561-1566.

[37] Boland C S, Khan U, Backes C, O’Neill A, Mccauley J, Duane S, Shanker R, Liu Y, Jurewicz I, Dalton A B, Coleman J N. Sensitive, high-strain, high-rate bodily motion sensors based on graphene-rubber composites. ACS Nano, 2014, 8, 8819-8830.

[38] Lee S, Reuveny A, Reeder J, Lee S, Jin H, Liu Q H, Yokota T, Sekitani T, Isoyama T, Abe Y, Suo Z G, Someya T. A transparent bending-insensitive pressure sensor. Nature Nanotechnology, 2016, 11, 472-478.

[39] Zang Y P, Zhang F J, Huang D Z, Gao X K, Di C A, Zhu D B. Flexible suspended gate organic thin-film transistors for ultra-sensitive pressure detection. Nature Communications, 2015, 6, 1-9.

[40] Pan L J, Chortos A, Yu G H, Wang Y Q, Isaacson S, Allen R, Shi Y, Dauskardt R, Bao Z N. An ultra-sensitive resistive pressure sensor based on hollow-sphere microstructure induced elasticity in conducting polymer film. Nature Communications, 2014, 5, 1-8.

[41] Amjadi M, Pichitpajongkit A, Lee S, Ryu S, Park I. Highly stretchable and sensitive strain sensor based on silver nanowire-elastomer nanocomposite. ACS Nano, 2014, 8, 5154-5163.

[42] Zhou J, Fei P, Gu Y D, Mai W J, Gao Y F, Yang R, Bao G, Wang $\mathrm{Z}$ L. Piezoelectric-potential-controlled polarity-reversible schottky diodes and switches of $\mathrm{ZnO}$ wires. Nano Letters, 2008, 8, 3973-3977.

[43] Liu Z Y, Qi D P, Guo P Z, Liu Y, Zhu B W, Yang H, Liu Y Q, Li B, Zhang C G, Yu J C, Liedberg B, Chen X D. Thickness-gradient films for high gauge factor stretchable strain sensors. Advanced Materials, 2015, 27, 6230-6237. 
[44] Qin Y Y, Peng Q Y, Ding Y J, Lin Z S, Wang C H, Li Y, Xu F, Li J J, Yuan Y, He X D, Li Y B. Lightweight, superelastic, and mechanically flexible graphene/polyimide nanocomposite foam for strain sensor application. ACS Nano, 2015, 9, 8933-8941.

[45] Choi S J, Yoo P J, Baek S J, Kim T W, Lee H H. An ultraviolet-curable mold for Sub-100-nm lithography. Journal of the American Chemical Society, 2004, 126, 7744-7745.

[46] Park B, Kim J, Kang D, Jeong C, Kim K S, Kim J U, Yoo P J, Kim T. Dramatically enhanced mechanosensitivity and signal-to-noise ratio of nanoscale crack-based sensors: Effect of crack depth. Advanced Materials, 2016, 28, 8068-8068.

[47] Ryu S, Lee P, Chou J B, Xu R Z, Zhao R, Hart A J, Kim S G. Extremely elastic wearable carbon nanotube fiber strain sensor for monitoring of human motion. ACS Nano, 2015, 9, 5929-5936.

[48] Lee G, Lee T, Choi Y W, Pikhitsa P V, Park S J, Kim S M, Kang D, Choi M. Metal-elastomer bilayered switches by utilizing the superexponential behavior of crack widening. Journal of Materials Chemistry C, 2017, 5, 10920-10925.

[49] Choi Y W, Kang D, Pikhitsa P V, Lee T, Kim S M, Lee G, Tahk D, Choi M. Ultra-sensitive pressure sensor based on guided straight mechanical cracks. Scientific Reports, 2017, 7, 1-8.

[50] Park J, Tahk D, Ahn C, Im S G, Choi S J, Suh K Y, Jeon S. Conformal phase masks made of polyurethane acrylate with optimized elastic modulus for 3D nanopatterning. Journal of Materials Chemistry C, 2014, 2, 2316-2322.

[51] Park B, Lee S, Choi H, Kim J U, Hong H, Jeong C, Kang D, Kim T I. A semi-permanent and durable nanoscale-crack-based sensor by on-demand healing. Nanoscale, 2018, 10, 4354-4360.

[52] Cho S H, White S R, Braun P V. Self-healing polymer coatings. Advanced Materials, 2009, 21, 645-649.

[53] Cui J X, Daniel D, Grinthal A, Lin K X, Aizenberg J. Dynamic polymer systems with self-regulated secretion for the control of surface properties and material healing. Nature Materials, 2015, 14, 790-795.

[54] Huynh T P, Sonar P, Haick H. Advanced materials for use in soft self-healing devices. Advanced Materials, 2017, 29, $1-14$.

[55] Lacour S P, Chan D, Wagner S, Li T, Suo Z G. Mechanisms of reversible stretchability of thin metal films on elastomeric substrates. Applied Physics Letters, 2006, 88, 2004-2007.

[56] Lipomi D J, Vosgueritchian M, Tee B C K, Hellstrom S L, Lee J A, Fox C H, Bao Z. Skin-like pressure and strain sensors based on transparent elastic films of carbon nanotubes. Nature Nanotechnology, 2011, 6, 788-792.

[57] Liu C X, Choi J W. Patterning conductive PDMS nanocomposite in an elastomer using microcontact printing. Journal of Micromechanics and Microengineering, 2009, 19, 085019.

[58] Maune H, Bockrath M. Elastomeric carbon nanotube circuits for local strain sensing. Applied Physics Letters, 2006, 89, 173131 .

[59] Kim Y J, Cha J Y, Ham H, Huh H, So D S, Kang I. Preparation of piezoresistive nano smart hybrid material based on graphene. Current Applied Physics, 2011, 11, S350-S352.

[60] Lee J, Kim S, Lee J, Yang D, Park B C, Ryu S, Park I. A stretchable strain sensor based on a metal nanoparticle thin film for human motion detection. Nanoscale, 2014, 6, 11932-11939.

[61] Wang C F, Zhao J, Ma C, Sun J L, Tian L, Li X Y, Li F T, Han X, Liu C T, Shen C Y, Dong L, Yang J, Pan C F. Detection of non-joint areas tiny strain and anti-interference voice recognition by micro-cracked metal thin film. Nano Energy, 2017, 34, 578-585.

[62] Liao F Y, Lu C, Yao G, Yan Z C, Gao M, Pan T S, Zhang Y, Feng $\mathrm{X}$, Lin $\mathrm{Y}$. Ultrasensitive flexible temperature-mechanical dual-parameter sensor based on vanadium dioxide films. IEEE Electron Device Letters, 2017, 38, $1128-1131$

[63] Sekitani T, Zschieschang U, Klauk H, Someya T. Flexible organic transistors and circuits with extreme bending stability. Nature Materials, 2010, 9, 1015-1022.

[64] Tee B C K, Wang C, Allen R, Bao Z. An electrically and mechanically self-healing composite with pressure- and flexion-sensitive properties for electronic skin applications. Nature Nanotechnology, 2012, 7, 825-832.

[65] Xu S, Zhang Y H, Jia L, Mathewson K E, Jang K I, Kim J, Fu H R, Huang X, Chava P, Wang R H, Bhole S, Wang L Z, Na Y J, Guan Y, Flavin M, Han Z S, Huang Y G, Rogers J A. Soft microfluidic assemblies of sensors, circuits, and radios for the skin. Science, 2014, 344, 70-74.

[66] Wang S, Xiao P, Liang Y, Zhang J W, Huang Y J, Wu S, Kuo S W, Chen T. Network cracks-based wearable strain sensors for subtle and large strain detection of human motions. Journal of Materials Chemistry C, 2018, 6, 5140-5147.

[67] Lee C J, Park K H, Han C J, Oh M S, You B, Kim Y S, Kim J W. Crack-induced Ag nanowire networks for transparent, stretchable, and highly sensitive strain sensors. Scientific Reports, 2017, 7, 7595. 
[68] Hong S K, Yang S, Cho S J, Jeon H, Lim G. Development of a waterproof crack-based stretchable strain sensor based on PDMS shielding. Sensors, 2018, 18, 1171.

[69] Han Z W, Liu L P, Zhang J Q, Han Q G, Wang K J, Song H L, Wang Z, Jiao Z B, Niu S C, Ren L Q. High-performance flexible strain sensor with bio-inspired crack arrays. Nanoscale, 2018, 10, 15178-15186.

[70] Lim S, Son D, Kim J, Lee Y B, Song J K, Choi S, Lee D J, Kim J H, Lee M, Hyeon T, Kim D H. Transparent and stretchable interactive human machine interface based on patterned graphene heterostructures. Advanced Functional Materials, 2015, 25, 375-383.

[71] Roh E, Hwang B U, Kim D, Kim B Y, Lee N E. Stretchable, transparent, ultrasensitive, and patchable strain sensor for human-machine interfaces comprising a nanohybrid of carbon nanotubes and conductive elastomers. ACS Nano, 2015, 9, 6252-6261.

[72] Park H, Jeong Y R, Yun J, Hong S Y, Jin S, Lee S J, Zi G, Ha J S. Stretchable array of highly sensitive pressure sensors consisting of polyaniline nanofibers and Au-coated polydimethylsiloxane micropillars. ACS Nano, 2015, 9, 9974-9985.

[73] Gong S, Schwalb W, Wang Y W, Chen Y, Tang Y, Si J, Shirinzadeh B, Cheng W L. A wearable and highly sensitive pressure sensor with ultrathin gold nanowires. Nature Communications, 2014, 5, 3132.

[74] Li X, Zhang R J, Yu W J, Wang K L, Wei J Q, Wu D H, Cao A Y, Li Z H, Cheng Y, Zheng Q S, Ruoff R S, Zhu H W. Stretchable and highly sensitive graphene-on-polymer strain sensors. Scientific Reports, 2012, 2, 870.

[75] Wang Z R, Wang S, Zeng J F, Ren X C, Chee A J Y, Yiu B Y S, Chung W C, Yang Y, Yu A C H, Roberts R C, Tsang A C O, Chow K W, Chan P K L. High sensitivity, wearable, piezoresistive pressure sensors based on irregular microhump structures and its applications in body motion sensing. Small, 2016, 12, 3827-3836.

[76] Park J, Kim M, Lee Y, Lee H S, Ko H. Nanomaterials: Fingertip skin-inspired microstructured ferroelectric skins discriminate static/dynamic pressure and temperature stimuli. Science Advances, 2015, 1, e1500661.

[77] Kim K K, Hong S, Cho H M, Lee J, Suh Y D, Ham J, Ko S H. Highly sensitive and stretchable multidimensional strain sensor with prestrained anisotropic metal nanowire percolation networks. Nano Letters, 2015, 15, 5240-5247.

[78] Lee T, Choi Y W, Lee G, Pikhitsa P V, Kang D, Kim S M, Choi M. Transparent ITO mechanical crack-based pressure and strain sensor. Journal of Materials Chemistry C, 2016, 4,
9947-9953.

[79] Lee T, Choi Y W, Lee G, Kim S M, Kang D, Choi M. Crack-based strain sensor with diverse metal films by inserting an inter-layer. RSC Advances, 2017, 7, 34810-34815.

[80] Lee E, Kim T, Suh H, Kim M, Pikhitsa P V, Han S, Koh J S, Kang D. Effect of metal thickness on the sensitivity of crack-based sensors. Sensors, 2018, 18, 2872.

[81] Yang P K, Lin Z H, Pradel K C, Lin L, Li X H, Wen X N, He J H, Wang Z L. Paper-based origami triboelectric nanogenerators and self-powered pressure sensors. ACS Nano, 2015, 9, 901-907.

[82] Wang Z H, Tammela P, Zhang P, Strømme M, Nyholm L. High areal and volumetric capacity sustainable all-polymer paper-based supercapacitors. Journal of Materials Chemistry A, 2014, 2, 16761-16769.

[83] Felton S, Tolley M, Demaine E, Rus D, Wood, R. A method for building self-folding machines. Science, 2014, 345, 644-646.

[84] Song H L, Zhang J Q, Chen D B, Wang K J, Niu S C, Han Z W, Ren L Q. Superfast and high-sensitivity printable strain sensors with bioinspired micron-scale cracks. Nanoscale, 2017, 9, 1166-1173.

[85] Yu A F, Chen X Y, Wang R, Liu J Y, Luo J J, Chen L B, Zhang Y, Wu W, Liu C H, Yuan H T, Peng M Z, Hu W G, Zhai J Y, Wang Z L. Triboelectric nanogenerator as a self-powered communication unit for processing and transmitting information. ACS Nano, 2016, 10, 3944-3950.

[86] Fan F R, Lin L, Zhu G, Wu W Z, Zhang R, Wang Z L. Transparent triboelectric nanogenerators and self-powered pressure sensors based on micropatterned plastic films. Nano Letters, 2012, 12, 3109-3114.

[87] Park J, Lee Y, Hong J, Lee Y, Ha M, Jung Y, Lim H, Kim S Y, Ko H. Tactile-direction-sensitive and stretchable electronic skins based on human-skin-inspired interlocked microstructures. ACS Nano, 2014, 8, 12020-12029.

[88] Domingo N, López-Mir L, Paradinas M, Holy V, Železný J, Yi D, Suresha S J, Liu J, Rayan Serrao C, Ramesh R, Ocal C, Martí X, Catalan G. Giant reversible nanoscale piezoresistance at room temperature in $\mathrm{Sr}_{2} \mathrm{IrO}_{4}$ thin films. Nanoscale, 2015, 7, 3453-3459.

[89] Viry L, Levi A, Totaro M, Mondini A, Mattoli V, Mazzolai B, Beccai L. Flexible three-axial force sensor for soft and highly sensitive artificial touch. Advanced Materials, 2014, 26, 2659-2664.

[90] Jiao W H, Yi L Z, Zhang C, Wu K, Li J, Qian L H, Wang S, Jiang Y T, Das B, Yuan S L. Electrical conduction of 
nanoparticle monolayer for accurate tracking of mechanical stimulus in finger touch sensing. Nanoscale, 2014, 6, 13809-13816.

[91] Ha M, Lim S, Park J, Um D S, Lee Y, Ko H. Bioinspired interlocked and hierarchical design of $\mathrm{ZnO}$ nanowire arrays for static and dynamic pressure-sensitive electronic skins. Advanced Functional Materials, 2015, 25, 2841-2849.

[92] Pang C, Lee G Y, Kim T I, Kim S M, Kim H N, Ahn S H, Suh K Y. A flexible and highly sensitive strain-gauge sensor using reversible interlocking of nanofibres. Nature Materials, 2012, 11, 795-801.

[93] Liao X Q, Zhang Z, Liao Q L, Liang Q J, Ou Y, Xu M X, Li M H, Zhang G J, Zhang Y. Flexible and printable paper-based strain sensors for wearable and large-area green electronics. Nanoscale, 2016, 8, 13025-13032.

[94] Liao X Q, Zhang Z, Liang Q J, Liao Q L, Zhang Y. Flexible, cuttable, and self-waterproof bending strain sensors using microcracked gold nanofilms@paper substrate. ACS Applied Materials and Interfaces, 2017, 9, 4151-4158.

[95] Kim T, Lee T, Lee G, Choi Y W, Kim S M, Kang D, Choi M. Polyimide encapsulation of spider-inspired crack-based sensors for durability improvement. Applied Sciences, 2018, $8,367$.

[96] Xiao Y, Jiang S W, Zhao X H, Jiang H C, Zhang W L. Crack-enhanced mechanosensitivity of cost-effective piezoresistive flexible strain sensors suitable for motion detection. Smart Materials and Structures, 2018, 27, 105049.

[97] Chen S, Wei Y, Wei S M, Lin Y, Liu L. Ultrasensitive cracking-assisted strain sensors based on silver nanowires/graphene hybrid particles. ACS Applied Materials and Interfaces, 2016, 8, 25563-25570.

[98] Amjadi M, Turan M, Clementson C P, Sitti M. Parallel Microcracks-based ultrasensitive and highly stretchable strain sensors. ACS Applied Materials and Interfaces, 2016, 8, 5618-5626.

[99] Albert J T, Friedrich O C, Dechant H E, Barth, F G. Arthropod touch reception: Spider hair sensilla as rapid touch detectors. Journal of Comparative Physiology A - Neuroethology Sensory Neural and Behavioral Physiology, 2001, 187, 303-312.

[100] Görner P, Claas B. Homing Behavior and Orientation in the Funnel-Web Spider, Agelena labyrinthica Clerck. Springer, Berlin Heidelberg, Germany, 1985.

[101] Barth F G, Wastl U, Humphrey J A C, Devarakonda R, Trans P, Lond R S. Dynamics of arthropod filiform hairs. II. Mechanical properties of spider trichobothria (Cupiennius salei Keys.). Philosophical Transactions of the Royal Soci- ety of London Series B: Biological Sciences, 1993, 340, 445-461.

[102] Meßlinger K. Fine structure of scorpion trichobothria. Zoomorphology, 1987, 107, 49-57.

[103] Hoffmann C. Bau und funktion der trichobothrien von euscorpius carpathicus. Zeitschrift Für Vergleichende Physiologie, 1967, 54, 290-352.

[104] Tautz J. Reception of particle oscillation in a medium - An unorthodox sensory capacity. Naturwissenschaften, 1979, 66, 452-461.

[105] Han Z W, Liu L P, Wang K J, Song H L, Chen D B, Wang Z, Niu S C, Zhang J Q, Ren L Q. Artificial hair-like sensors inspired from nature : A review. Journal of Bionic Engineering, 2018, 15, 409-434.

[106] Barth F G, Holler A. Dynamics of arthropod filiform hairs. V. The Response of Spider Trichobothria to Natural Stimuli. Philosophical Transactions: Biological Sciences, 1999, 354, 183-192.

[107] Devarakonda R, Barth F G, Humphrey J A C. Dynamics of arthropod filiform hairs. IV. Hair motion in air and water. Philosophical Transactions: Biological Sciences, 1996, 351, 933-946.

[108] Shimozawa T, Kumagai T, Baba Y. Structural scaling and functional design of the cercal wind-receptor hairs of cricket. Journal of Comparative Physiology A - Neuroethology Sensory Neural and Behavioral Physiology, 1998, 183, $171-186$

[109] Shimozawa T, Kanou M. Varieties of filiform hairs: Range fractionation by sensory afferents and cereal interneurons of a cricket. Journal of Comparative Physiology A - Neuroethology Sensory Neural and Behavioral Physiology, 1984, 155, 485-493.

[110] Görner P, Andrews P. Trichobothrien, ein Ferntastsimmsorgan bei Webespinnen. Zeitschrift Für Vergleichende Physiologie, 1969, 64, 301-317.

[111] Reißland A, Görner P. Mechanics of trichobothria in orb-weaving spiders (Agelenidae, Araneae). Journal of Comparative Physiology A - Neuroethology Sensory Neural and Behavioral Physiology, 1978, 123, 59-69.

[112] Bathellier B, Barth F G, Albert J T, Humphrey J A C. Viscosity-mediated motion coupling between pairs of trichobothria on the leg of the spider Cupiennius salei. Journal of Comparative Physiology A - Neuroethology Sensory Neural and Behavioral Physiology, 2010, 196, 89-89.

[113] Görner P. A proposed transducing mechanism for a multiply-innervated mechanoreceptor (Trichobothrium) in spiders. Cold Spring Harbor Symposia on Quantitative Biology, 
1965, 30, 69-73.

[114] Park J, Lee Y, Hong J, Ha M, Jung Y Do, Lim H, Kim S Y, Ko H. Giant tunneling piezoresistance of composite elastomers with interlocked microdome arrays for ultrasensitive and multimodal electronic skins. ACS Nano, 2014, 8, 4689-4697.

[115] Chun S, Son W, Choi C, Min H, Kim J, Lee H J, Kim D, Kim C, Koh J S, Pang C. Bioinspired hairy skin electronics for detecting the direction and incident angle of airflow. $A C S$ Applied Materials and Interfaces, 2019, 11, 13608-13615.

[116] Alfadhel A, Li B, Zaher A, Yassine O, Kosel J. A magnetic nanocomposite for biomimetic flow sensing. Lab on a Chip, 2014, 14, 4362-4369.

[117] Droogendijk H, de Boer M J, Sanders R G P, Krijnen G J M. Bio-inspired hair-based inertial sensors. Biomimetic Technologies, 2015, 93-119.

[118] Droogendijk H, de Boer M J, Sanders R G P, Krijnen G J M. A biomimetic accelerometer inspired by the cricket's clavate hair. Journal of the Royal Society Interface, 2014, 11 20140438.

[119] Maschmann M R, Ehlert G J, Dickinson B T, Phillips D M, Ray C W, Reich G W, Baur J W. Bioinspired carbon nanotube fuzzy fiber hair sensor for air-flow detection. Advanced Materials, 2014, 26, 3230-3234.

[120] Liu Z Y, Qi D P, Leow W R, Yu J C, Xiloyannnis M, Cappello L, Liu Y Q, Zhu B W, Jiang Y, Chen G, Masia L, Liedberg B, Chen X D. 3D-structured stretchable strain sensors for out-of-plane force detection. Advanced Materials, 2018, 30, 1707285.

[121] Sadeghi M M, Peterson R L, Najafi K. Micro-hydraulic structure for high performance bio-mimetic air flow sensor arrays. IEEE International Electron Devices Meeting, Washington D C, America, 2011, 673-676.

[122] Liu Y F, Huang P, Li Y Q, Liu Q, Tao J K, Xiong D J, Hu N, Yan $\mathrm{C}$, Wang $\mathrm{H}, \mathrm{Fu} \mathrm{S}$ Y. A biomimetic multifunctional electronic hair sensor. Journal of Materials Chemistry A, 2019, 7, 1889-1896.

[123] Yin B, Liu X M, Gao H Y, Fu T D, Yao J. Bioinspired and bristled microparticles for ultrasensitive pressure and strain sensors. Nature Communications, 2018, 9, 5161.

[124] Alfadhel A, Kosel J. Magnetic nanocomposite cilia tactile sensor. Advanced Materials, 2015, 27, 7888-7892.

[125] Alfadhel A, Khan M A, Cardoso S, Leitao D, Kosel J. A magnetoresistive tactile sensor for harsh environment applications. Sensors, 2016, 16, UNSP 650.

[126] Ding L, Pei L, Xuan S H, Fan X W, Cao X F, Wang Y, Gong X L. Ultrasensitive multifunctional magnetoresistive strain sensor based on hair-like magnetization-induced pillar forests. Advanced Electronic Materials, 2019, 6, 1900653.

[127] Han H, Baik S, Xu B, Seo J, Lee S, Shin S, Lee J, Koo J H, Mei Y F, Pang C, Lee T. Bioinspired geometry-switchable Janus nanofibers for eye-readable $\mathrm{H}_{2}$ sensors. Advanced Functional Materials, 2017, 27, 1701618.

[128] Ko H, Song H, Im S, Kim H, Jang B, Shim H, Cho D D. Bioinspired piezoresistive acceleration sensor using artificial filiform sensillum structure. Sensors and Materials, 2015, 27, 437-445.

[129] Mondal I, Kumar A, Rao K D M, Kulkarni G U. Parallel cracks from a desiccating colloidal layer under gravity flow and their use in fabricating metal micro-patterns. Journal of Physics and Chemistry of Solids, 2018, 118, 232-237.

[130] Huang K Y, Huang C T. Hair sensor using a photoelectronic principle for sensing airflow and its direction. Optical Engineering, 2011, 50, 014402.

[131] Takei K, Honda W, Harada S, Arie T, Akita S. Toward flexible and wearable human-interactive health-monitoring devices. Advanced Healthcare Materials, 2015, 4, 487-500.

[132] Zhou Y J, Zhan P F, Ren M N, Zheng G Q, Dai K, Mi L W, Liu C T, Shen C Y. Significant stretchability enhancement of crack-based strain sensor combined with high sensitivity and superior durability for motion monitoring. ACS Applied Materials \& Interfaces, 2019, 11, 7405-7414.

[133] McEvoy M A, Correll N. Materials that couple sensing, actuation, computation, and communication. Science, 2015, 347, 1261689.

[134] Polygerinos P, Wang Z, Galloway K C, Wood R J, Walsh C J. Soft robotic glove for combined assistance and at-home rehabilitation. Robotics \& Autonomous Systems, 2015, 73, 135-143.

[135] Majidi C. Soft robotics: A perspective-current trends and prospects for the future. Soft Robotics, 2013, 1, 5-11.

[136] Gong S, Lai D T H, Su B, Si K J, Ma Z, Yap L W, Guo P Z, Cheng W L. Highly stretchy black gold E-skin nanopatches as highly sensitive wearable biomedical sensors. Advanced Electronic Materials, 2015, 1, 1400063. 